\title{
OBLIGATIO: IN IURE CONSISTUNT ${ }^{1}$
}

\author{
OBLIGATIO: IN IURE CONSISTUNT
}

\section{Cristián Aedo Barrena ${ }^{2}$}

\begin{abstract}
RESUMEN: El presente artículo aborda el concepto de la obligación en Roma desde tres perspectivas: el sentido etimológico de la expresión, las teorías sobre su origen y desarrollo, para terminar con la formulación clásica del concepto. En este punto, nos hemos detenido en las definiciones de Paulo y Justiniano, para concluir con la lectura procesal. En esta materia, se reflexiona sobre el la naturaleza de la obligatio, concretamente, qué han querido expresar los pasajes de Gayo 2, 14 y Justiniano 2, 2, 3, al referirse a la obligatio como iura. En la última parte del artículo se analizan las herramientas a favor del acreedor, en el caso de incumplimiento contractual.
\end{abstract}

Palabras clave: Obligatio, iura, deudor, acreedor, manus iniectio, delitos, sponsio

ABSTRACT: This article discusses the concept of obligation in Rome from three perspectives: the etymological sense of the term, theories about its origin and development, ending with the classical formulation of the concept. At this point, we stopped in the definitions of Paulo and Justinian, to conclude with the reading procedural law. In this matter, it reflects on the nature of the obligatio, specifically, which have sought to express the passages of Gaius 2, 14 and Justinian 2, 2, 3, referring to the obligatio as iura. In the last part of the article discusses the remedies to the creditor, in the case of breach of contract.

Key words: Obligatio, iura, debitor, creditor, manus iniectio, delict, sponsio

\section{INTRODUCCIÓN}

La obligatio constituye, sin duda alguna, uno de los conceptos jurídicos fundamentales. Una importante construcción del campo dogmático moderno se debe a dicho concepto. Articula materias que van desde los derechos reales, pasando por el Derecho de familia, para retornar al propio campo de la obligación. Ninguna de sus fuentes puede comprenderse sin incorporar en su análisis la categoría dogmática de la obligación.

La aparición de la figura puede remontarse, desde luego, al Derecho romano, pero una evolución y análisis de la misma no está exenta de dificultades, ni de discusión. Talamanca nos recuerda que la doctrina relativa al origen y evolución del instituto no puede ser segura: "Bisogna, anzitutto, premettere la considerazione che la scarsissime fonti a nostra disposizione per il periodo risalente non permettono anche qui di proporre in alcun senso una

1 Este trabajo ha sido elaborado como parte del FONDECYT de Iniciación No 11121533, denominado "Las relaciones entre culpa y causalidad: una explicación desde el Derecho Romano” y del Proyecto Anillo de Investigación Asociativa, en Ciencias Sociales, "Estudios Histórico-Dogmáticos de Derecho Patrimonial Privado: una mirada a los artículos de los Libros II y IV del Código Civil de Chile”, SOC 1111, de CONICYT. Agradezco los valiosos comentarios de los profesores Carlos Amunátegui Perelló y Ericka Castellanos Moreno.

2 Decano de la Facultad de Ciencias Jurídicas de la Universidad Católica del Norte. Doctor en Derecho por la Universidad de Deusto. Profesor de Derecho romano y civil en la Universidad Católica del Norte. Correo electrónico: caedo@ucn.cl. 
ricostruzione suficientemente argomentata, ma soltanto di individuare qualche linea tendenziale di sviluppo, soprattutto attraverso l'esercizio di un'opzione personale all'interno delle varie possibilità intrepretative che si offrono, ciò in cui possono aver peso-ed effettivamente l'hanno avuto- le personali convinzioni circa modelli astratti d'evoluzione"3.

El presente artículo se divide en dos partes. En la primera parte, con la sabia advertencia de Talamanca, el trabajo intentará remontarse a los orígenes de la obligatio y explicar su evolución desde las fuentes, hasta llegar a la reconstrucción del concepto en época clásica. En una segunda parte, estudiaremos el carácter de ius que la obligatio tuvo, según Gayo y Justiniano, y cómo dicho carácter incide en la consideración de la naturaleza del crédito.

\section{LA ETIMOLOGÍA DE LA PALABRA OBLIGATIO}

Obligatio constituye un sustantivo abstracto que designa la acción derivada del verbo obligare $^{4}$, el que, a su vez, se compone del prefijo $o b$ y de la forma verbal simple ligare. De acuerdo con los diccionarios especializados, la fórmula verbal obligo, as, are, tiene los siguientes significados etimológicos: a) atar juntos, reunir, ligar, envolver, vendar (especialmente en algunos pasajes de Cicerón, relativo a las vendas de una herida); b) ligar, encadenar; c) en otro sentido, referido al sujeto, hacerse culpable de una falta y, por conexión, hipotecar o empeñar, en un sentido lato; d) exigir al sujeto hacerse responsable; e) comprometerse a seguir los actos o jurar obediencia a los actos de alguno 5 .

Como indica Pieri, el sustantivo obligatio es relativamente tardío en la lengua latina (no pudiendo precisarse exactamente la época de aparición), pues salvo el empleo por Cicerón, no figura entre los juristas latinos. En cambio, advierte, el verbo obligare, tenía un antiguo uso general ${ }^{6}$. Especialmente, siguiendo al autor, el verbo obligari se empleaba para designar a la persona culpable de un delito; en otros términos, a la sujeción del culpable de dicho delito con su víctima; o bien para referirse a la pena aplicable al responsable. Así, Cicerón utiliza el verbo obligare en un sentido general, para designar una cosa consagrada a los dioses (religione obligata) ${ }^{7}$; bien para indicar que una cosa ha salido del comercio, al en-

\footnotetext{
3 Talamanca (1979) p. 9. Podemos encontrar un desacuerdo tan fundamental, como en lo que sigue: Cannata considera la obligatio como una noción estrictamente jurídica, no teniendo ninguna correspondencia prejurídica o económica: ... è una nozione strettamente tecnica, un puro strumento operativo", véase CANNATA (2003) p. 15. Por el contrario, otro romanista, Fernández de Buján indica: "El concepto de obligación es un concepto metajuridico. Una persona puede sentirse obligada respecto a otra por razones familiares, morales, profesionales... en la medida que se considera constreñida respecto de ella". No obstante, reconoce que, el sentido propio de la expresión, nace en razón del Derecho, es decir, que en las culturas primitivas, no se le encontrará, por cuanto en ellas no se requiere dicha elaboración, véase Fernández de Buján (2004) pp. 43; 45.

4 Véase, en este sentido, Blánquez Fraile (1961) pp. 1129, v. obligatio, referida, desde el punto de vista jurídico, a un deber.

5 Véase, entre otros, De Miguel (1861) p. 622; Körting (1907) p. 697; De Valbuena (1860) p. 636.

6 Pieri (1990) pp. 222; 224. Como indica Schulz puede remontarse el verbo a las comedias de Plauto, en cuyas obras es usada en su sentido literal y metafóricamente. Contrariamente, agrega, el sustantivo aparece solo en la obra de Cicerón, véase Schulz (1960) p. 435.

7 En este sentido lo emplea Cicerón, por ejemplo, en De Legibus, Lib. I, XXIII, (58): "Sed <ut> in urbe sepeliri lex vetat, sic decretum a pontificum collegio, non esse ius in loco publico fieri sepulcrum. Nostis extra portam Collinam aedem Honoris. Aram in eo loco fuisse memoriae proditum est. Ad eam cum lamina esset inventa, et in ea scriptum <lamina> 'Honoris', ea causa fuit <ut> aedis haec dedicare<tur>. Sed quom multa in eo loco sepulcra fuissent, exarata sunt. Statuit enim collegium locum publicum non potuisse privata religione obligari”.
} 
contrarse sujeta a título de garantía en favor de otro ${ }^{8}$; entre las personas, pues estas, refiere Pieri, en las obras de Cicerón, pueden estar vinculadas por un beneficio, una liberalidad? Sin embargo, en su sentido propiamente jurídico, reflejaba un vínculo contraído: “...en raison de crimes, de peines ou por la verba de la sponsio" 10 . Fue, en este sentido, sinónimo de nectere, de donde deriva el sustantivo nexum.

En cuanto al sustantivo, este representará un proceso de abstracción del término vínculo, traducido en el acto de ligar y atar. De este modo, reflejaba el acto de ligar a dos sujetos en virtud de formas específicas. Así, por ejemplo, obligatio no designaba la obligación del mandatario, sino el acto mismo que vinculaba ${ }^{11}$.

De este modo, encontramos todos los elementos que derivan de la etimología de la palabra, que nos permitirá indagar el significado romano de la obligación. Por un lado, ha de reconocerse que el origen de la obligatio (en particular, del verbo que le da origen), se conecta y, más aún se confunde, con sus causas. Obligación representa en un estadio primitivo, tanto aquello que da origen al vínculo, como el vínculo mismo ${ }^{12}$. Como indica Cannata, el concepto de obligatio, en el lenguaje de los juristas romanos, significaba tanto relación obligatoria, como acto y efecto obligatorio ${ }^{13}$. Y, todavía más, como ha explicado Purpura, el vínculo personal que suponía la obligatio y la apropiación del cuerpo por parte del deudor, obedecería a la antigua analogía entre la obligación y el dominio. El acreedor era dueño del cuerpo del deudor, al punto que este podía verse privado de una adecuada sepultura frente a la insatisfacción del acreedor ${ }^{14}$.

En segundo lugar, es sintomático que, en este estadio primitivo, la noción aparezca vinculada con los delitos. Algo similar ocurrió con la fuente contractual y el efecto obligatorio subsecuente. El verbo obligare se refería antes que a una consecuencia, a un acto: el de atar. Este aserto se comprueba cuando es el nexum el que se asocia como antecedente de la obligatio, representando este acto y efecto a la vez ${ }^{15}$.

Sin embargo, la romanística moderna ha discutido, entre otras cuestiones, el origen de la obligatio. Como veremos, algunos autores ponen en cuestión de que su nacimiento se encuentre en los delitos; por el contrario, se asegura, la verdadera fuente primitiva de la obligación romana, hay que buscarla en el acuerdo contractual ${ }^{16}$.

\footnotetext{
8 Pieri cita el pasaje 2, 5, 10 de Catilina de Cicerón, que, en efecto, se refiere al agotamiento de las garantías patrimoniales de los acusados, en términos eufemísticos: "Patrimonia sua profuderunt, fortunas suas obligaverunt; res eos iam pridem deseruit, fides nuper deficere coepit; eadem tamen illa, quae erat in abundantia, lubido permanet", véase PIERI (1990) p. 222.

9 Pieri (1990) p. 222.

10 Pieri (1990) pp. 222-223.

11 Pieri (1990) p. 225.

12 Véase Dumont (1963) p. 78; Santoro (2001) p. 260. Disponible en <www.ledonline.it/rivistadirittoromano (fecha de la consulta: 10 de abril de 2013)>.

13 Cannata (2003) p. 13.

14 Purpura (2009) pp. 45; 48.

15 Como dice Gaudement p. 148, el verbo obligare, como otros verbos referidos a materias jurídicas, designó la acción, antes que el resultado; mancipatio, contestatio, dedicatio; en otros términos, el acto que liga, antes que el efecto de encontrarse ligado, véase Gaudement (2001) p. 148.

16 Por eso, no puede afirmarse tan categóricamente, su origen delictual, como se hace en nuestra dogmátiva civil. Véase, por ejemplo, Abeliuk: "Se creé que en Roma, como en otras civilizaciones, el concepto de obligación nació en las sociedades primitivas como consecuencia de la eliminación de la venganza privada y su reemplazo por una composición
} 


\section{3. ¿CUÁL ES EL ORIGEN DE LA OBLIGATIO: DELICTUAL O CONTRACTUAL?}

\section{A. Su posible origen EN los Delitos}

Mirado el origen de la obligación desde la perspectiva del delito, no cabe duda que se encuentra una profunda raíz religiosa. Como indica Dumont, la noción jurídica del vínculo (con independencia a su referencia material), tenía antecedentes religiosos. El hombre se veía atado a la venganza divina ${ }^{17}$.

Desde la perspectiva del delito, subyace en todas las culturas primitivas (incluyendo la griega y la romana), la idea del delito como fatalidad, como destino divino que sujetaba a una persona a un fin determinado. Siguiendo a Mair, tal como ocurre en el Derecho romano, se consideraba que en los primeros estadios del Derecho griego, tanto el delito como la sanción estaban fundados en la significación objetiva del pecado, encontrándose ausente la conciencia de falta. Dado que el pecado debía ser inevitablemente punido y sancionado, directa y materialmente, aquí y ahora, las mentes primitivas simplemente inferían que si un hombre sufría una mala fortuna, él había pecado u ofendido a los dioses ${ }^{18}$. Como expresa Gaudement, la explicación mágico-religiosa de la obligatio importa la idea de una venganza divina en contra de quien había actuado contra los designios divinos ${ }^{19}$. En esta línea, Peppe ha argumentado que la vindicta vino a representar la pax deorum, que había sido turbada por el incumplimiento de la obligación ${ }^{20}$.

económica, esto es, como un derivado de los hechos ilicitos. Se celebrara entonces un acuerdo entre ofensor y ofendido, impregnado de formalismo y religiosidad, en que el primero pasaba a tener la categoría de obligado a la reparación. El desarrollo económico de los pueblos y su mayor cultura fueron ampliando cada vez más el número de los negocios jurídicos pero en el primitivo Derecho Romano el concepto de obligación estuvo dominado por el origen de esta; la obligación nacía de un acto formal, de carácter religioso y marcado por el subjetivismo. En virtud de semejante pacto, el deudor quedaba atado en su persona al acreedor, quien adquiría derechos en la persona física de aquel (manus injectio). Un último rastro de semejante concepción se mantuvo hasta hace muy poco tiempo: la prisión por deudas. La obligación evolucionó en el Derecho Romano, pero nunca logró desprenderse integralmente de su marcado subjetivismo y formalismo", véase AвELıuk (2001) p. 25. Una visión similar entrega Peñailillo: "Es opinión generalmente aceptada que en las civilizaciones primitivas (asi también en los orígenes de Roma) la obligación y sus estatuto habrían nacido al comenzar a aceptarse la sustitución de la venganza privada por la indemnización a la víctima; es decir, como consecuencia de lo que hoy llamamos hechos ilícitos", véase PeñaIlillo (2003) p. 35. Más cauto Fueyo, en efecto, describe la evolución desde la perspectiva de la sujeción personal, en términos de esclavitud, de una persona para con su acreedor, para hacer luego un paralelismo con la evolución de los conceptos de delito y pena, véase Fueyo (2001) pp. 22-25. Este extremo es expresamente criticado por Betti, como tendremos oportunidad de analizar.

17 Dumont (1963) p. 78.

18 Mair (1962) p. 546. Como explica Rodhe, en la tragedia de Esquilo, que recoge leyendas y tradiciones antiguas, era común la idea de que los crímenes de los antepasados atraían un castigo, aquí en la tierra, sobre sus descendientes. De algún modo, nuestras sociedades no han podido desprenderse de este carácter primitivo en la concepción de las causas y las consecuencias negativas en la vida. Mucho de lo que consideramos primitivo, se ha incorporado de tal modo en nuestras formas de vida social, que forman parte de nuestras relaciones cotidianas. RodHe (1994) p. 223.

19 Dice el autor: "Puis serait intervenue l'idée d'una vengeance divine contre celui qui ne respectait pas son engagement. Ici encore les formes de cette vengeance, ses manifestations restent dans l'obscurité. Finalement on serait passé du lien mágico-religieux au lien juridique. Resterait à dire pourquoi, quand et comment". Gaudement (2001) p. 149. Por ello, Cesarini Sforza advierte que en todas las culturas primitivas la obligación entraña la convicción de que la propia acción depende de la voluntad de otro. Cesarini Sforza (1968) p. 662.

20 Peppe (2009) p. 142. 
La conexión entre el vínculo y el delito, se aprecia también en el nexum. Etimológicamente, algunos autores consideran que este proviene de nectere: ligar, al igual que obligare, pero hay quien ha considerado inevitable asociar el nexum romano con el nekes griego, que significaba acto de muerte. Y por ello, como indica Dumont, los tres verbos que utiliza Cicerón, adligere, obstringere y obligare, con independencia de su sentido primigenio de atar, amarrar, tenían como sentido secundario el de acto culpable ${ }^{21}$. En efecto, como indica Pérez Alvarez, primitivamente el deudor quedaba expuesto a una damnatio, una maldición destinada por los dioses en caso de incumplimiento ${ }^{22}$.

No debe perderse de vista que la expresión culpa, antes que referirse al estado de quien provoca un resultado, supone un reproche y, en este sentido, atribución de responsabilidad. Así, en el Oxford Latin Dictionary se explica que, en general, la expresión culpa supone la responsabilidad misma derivada de algún daño, la conducta reprobable, el reproche de una conducta - in a esse-; ser reprochable, tener una falta -a est-; es mi o su falta; formular un reproche a alguien; causa de reproche, reprobación ${ }^{23}$.

La idea de la obligatio como consecuencia derivada del delito, ha sido expuesta, entre otros, por Zimmermann. Según el autor, las raíces de la obligatio se encuentran, en el antiguo Derecho romano, en las relaciones jurídicas que giraron en torno a la familia. Las cuestiones sucesorias y la propiedad eran los problemas jurídicos que se les presentaron a los antiguos romanos, en una sociedad de carácter elementalmente rural ${ }^{24}$. La familia representaba una unidad, por sobre todo, religiosa, agrupados en torno a los antepasados comunes (sacrae familiaria). También se presentaba como una unidad económica, que se dedicaba a la explotación de los bienes familiares (mancipi: el inmueble familiar, el huerto, los animales de tiro y carga; y, los esclavos). El paterfamilias era el varón jefe de la familia. Era el único que detentaba capacidad jurídica, poder de mando y dominium. La familia era, así, una institución a favor del padre. Solo el cristianismo sentó el principio de que la familia está a favor de los hijos ${ }^{25}$.

\footnotetext{
21 Dumont (1963) p. 84.

22 Pérez Állvarez (2011) p. 2.

23 Glare (1983) pp. 465-466. Debe agregarse, siguiendo en este punto a Castresana que ya en las primeras fuentes latinas, la palabra culpa fue empleada en un sentido muy amplio, como sinónimo de culpabilidad. En otras palabras, que en un sentido originario la expresión fue utilizada para referirse a la acción imputable, culpable y desde ahí al principio de culpabilidad como imputabilidad de una conducta voluntaria, especialmente en Cicerón. Como dice la autora: "Todas estas reflexiones ciceronianas en torno al concepto de culpa como culpabilidad del agente que realiza injustificadamente una conducta lesiva que le es asi imputable y que, por ello fundamenta la responsabilidad por damnum, son reflexiones muy presentes en la interpretatio de la Jurisprudencia romana, ya desde finales de la República". Más importante aún es que esta autora agregue que la culpa con sentido de culpabilidad no difería de la iniuria como elemento de la lex Aquilia, desde que la iniuria implicaba un resultado antijurídico, pero desde un sujeto se encontraba en una situación que infería daño. La conclusión es relativamente simple si se arranca del supuesto que, en un período u otro la culpa llegó a ser equiparada con la iniurialo que constituye una opinión generalizada, véase CASTRESANA (2001) pp. 60. En este sentido y por todos, véase, MacCormack (1974) p. 201.

24 Zimmermann (1996) pp. 1-3. Véase, entre otros, Bonfante (1979) pp. 34 y ss.: "La fonte primitiva dell'obbligazione è il delitto... ”. La pecunia sería un sucedáneo de la disposición del cuerpo del ofensor.

25 Como ocurre con la mayoría de las instituciones jurídicas, es muy controvertido el significado de la familia en Roma. Una excelente explicación de estas teorías se encuentra en Amunátegui Perelló (2009) pp. 25-29.
} 
Las únicas situaciones que comenzaron a escapar de este ámbito de control del padre de familia, siguiendo siempre a Zimmermann, decían relación con las acciones dirigidas contra un tercero para la sanción de un mal causado. El ejercicio de los poderes del padre, entonces, no estaban dirigidos a incorporar a una persona a su familia, sino obtener una retribución ${ }^{26}$. Desde luego, la primera respuesta fue tomar la autoridad en propia mano, es decir, los mecanismos de autotutela o autodefensa, aunque, en la medida de que paulatinamente el Estado asumió las funciones de administración de los conflictos, la vindicta se vio transformada por la idea de la poen $a^{27-28}$. Betti coincide en que la obligación no era un vínculo entre sujetos de la misma familia, sino necesariamente, entre extraños; por el contrario, agrega, las relaciones de la familia estuvieron circunscritas a la patria potestas y a la manus. Se trataba, en consecuencia, de relaciones entre iguales. No obstante, entiende que dicha cuestión no autoriza a suponer que el origen de la obligatio se encuentre en los delitos ${ }^{29}$.

Precisamente, importantes romanistas critican la idea de que la obligatio tenga su origen en los delitos. En particular, Betti, estima que dicha idea supone una confusión entre la obligación y la acción penal; de otro, también revela la confusión entre el concepto de responsabilidad, en el sentido de garantía, con el término desde la perspectiva penal. Entre sus diferencias, Betti se preocupa de destacar algunas: la poena, como mecanismo sustitutivo de la vindicta, supuso la respuesta del ordenamiento frente a un hecho pasado; se trataba, en consecuencia, de reemplazar el valor perdido con una suma de dinero (que no cumplía, por cierto, un valor compensatorio). En cambio, la genuina obligatio, particularmente, la responsabilidad, entendida como garantía, entrañaba la respuesta frente a un hecho futuro (la frustración de la expectativa del acreedor). Por estas mismas razones, en el pensamiento de Betti, hay una razón para negar el carácter de obligación a la consecuencia derivada de delito: la vindicta no admitía la solutio, pues el pago de la suma de dinero, como consecuencia de la poena, era un acuerdo posterior al delito ${ }^{30}$.

\footnotetext{
26 Zimmermann (1996) p. 3. En Guzmán Brito, "La idea de obligación como vinculo jurídico entre personas que permite a una exigir prestaciones de la otra, fue el resultado de la evolución iniciada en la primordial experiencia del comportamiento dañoso que alguien puede asumir frente a un coasociado, y del natural deseo de venganza que entonces surge en la víctima; dicho de otra manera, en aquel ámbito que con terminología posterior se llamó de los delitos". GUZMÁn Brito (2001) p. 674.

${ }^{27}$ La noción de delito deriva del latín delictum, que, según PugliatTI, viene del verbo delinquere, compuesto de la raíz linquere, como sinónimo de la raíz italiana lasciare, que se traduce en el verbo abandonar o dejar, en lengua castellana. Véase, Pugliatti (1965) p. 1. Agrega el autor que en la lengua latina, común y técnica, existieron varias voces sinónimas de la expresión delito, como maleficium, flagitium, scelus, facinus, peccatum, crimen.

${ }^{28}$ Es común distinguir, en la dogmática romanística, entre los delitos y los crimina. En efecto, junto a los delitos públicos (crimina), que suponen atentados al orden público y se castigan en la jurisdicción criminal (quaestiones perpetuae), existen los delitos privados (delicta), cuya finalidad es conseguir una condena pecuniaria. No obstante, como aclara D'Ors, la diferencia termonológica no fue del todo rigurosa entre los juristas romanos, véase D’Ors (1997) p. 423.

29 Indica Betti: "Se poi si attribuice importanza decisiva al sintomo che si desume el carattere necesariamente interfamiliare del «vinculum iuris", siccome rapporto che non può costituirsi all'interno di una famiglia romana ma solo all'esterno della famiglia, fra il paterfamilias e persona estranea all'organismo familiare". Ветті (1955) pp. 55; 91.

30 Bетті (1955) pp. 97-98; 104; 107. Es un argumento que Betti se preocupa de repetir permanentemente, por ejemplo: "...Quando in una simile situazione l'offeso, che aveva esperito o stava per esperire la manus iniectio, cominciò a consentiré al colpavole di far la pace (pacisci) e a convenire una composizione (damnum decidere), questa non ebbe, per il colpavole, il carattere giuridico di riscatto da un vincolo (solutio), quando piuttosto il carattere di
} 
Como indica Cannata, la pena era una sanción (no una reparación), aun cuando consistiera en una suma de dinero. Tanto es así que llega a la conclusión que la obligación ex delicto fue una estructura ausente de las XII Tablas, por cuanto los diversos ilícitos sancionados en estas no significaban el nacimiento de un vínculo obligatorio civil entre ofendido y ofensor. Esta se entendía, por tanto, como una opción que podía ser objeto de pactos o que podía ser aceptada como cuantía personal (composición voluntaria o legal, respectivamente). Si el dañante no resarcía el daño, debía entregarse personalmente al danado ${ }^{31}$.

Este juicio es compartido por Talamanca. Según el autor, la sujeción de una persona, es decir, su responsabilidad para con otro, no se tradujo inmediatamente en una obligación, puesto que esta supuso que la responsabilidad se derivaba solo de la falta de cumplimiento de la expectativa del acreedor, cuestión que no ocurría en los delitos: "Una responsabilità, come soggezione ad una sanzione, si ha, infatti, sia nel fatto illecito, comunque punito, sia nell'atto lecito con cui un soggetto si assuma la garenzia per l'aspettativa del creditore. Ma assoggettamento ad una sanzione non significa, di per se stesso, obbligazione: la caratteristica differenziale di quest'ultima figura è che la responsabilità venga collegata al mancato soddifacimento di un'aspettativa e che si dia, quindi, un periodo di pendenza della responsabilità stessa fin tanto che non si sia accertato se l'aspettativa del creditore sia stata frustrata o meno"32.

Así, en la argumentación de Talamanca, como en la de Betti, la vindicta no puede ser confundida con la obligatio; en otros términos, no es obligación la mera sujeción del ofensor a la víctima: esta podrá surgir siempre que, del delito, traducido en una pena, se frustre para el acreedor, la expectativa del cumplimiento ${ }^{33}$. Por eso, una explicación del origen de la obligatio que no se haga cargo de la diferencia, no constituye una explicación adecuada del origen del instituto.

Es claro que la poena pecuniaria es la base de la obligatio, pero, en esta línea argumental, no debe confundirse con esta. La poena fue el mecanismo que vino a reemplazar la venganza privada, no perseguía, por el contrario, satisfacer la expectativa del acreedor, al menos inmediatamente $^{34}$. Siguiendo siempre a De Visscher, las características de los delitos, cons-

un'espiazione o di un prezzo della pace, che era da pagare appena convenuto", véase BetTI (1955) p. 135. Véase, en un sentido similar, De Visscher (1928) p. 342.

31 Cannata (1992) pp. 25; 27. En el mismo sentido, Fuenteseca Degeneffe (1997) pp. 127-129. De hecho, como apunta De Vischer, en Gayo III, párrafos 183 a 225, no se menciona la expresión obligatio, salvo en dos párrafos, pues el tratamiento se centra en la poena. En el primero, párrafo 193, obligari furti significa hacer responsable al autor del ilícito; en la segunda, párrafo 208 (se emplea la expresión obligari), en su conjunto se considera un párrafo interpolado. Por diferencia, en los párrafos relativos a los contratos se emplea a menudo y, en sentido técnico, la expresión. De VIsCher (1928) pp. 353-354.

32 Talamanca (1979) p. 2.

33 "Come accade quando all'offensore sia imposta una poena pecuniaria a favore della persona offesa dal fatto illecito, ciò que darà, appunto, luogo alla configurazione dell'obligatio ex delicto. La soggenzione pura e semplice alla vindicta dell'offeso non può, dunque, configurare un'obbligazione, a meno di scolorire questo termine sino a ricomprendervi qualsiasi responsabilità, conmunque strutturada". TALAMANCA (1979) p. 3.

34 Según Albanese, la palabra poena tenía en el Derecho romano dos sentidos precisos. En un primer sentido, poena era la aflicción conexa del ordenamiento jurídico al comportamiento antijurídico. En el segundo significado técnico, por el contrario, poena era la aflicción pecuniaria determinada, a cargo de un sujeto, en base a una obligación libremente asumida frente al otro sujeto, como ocurrió con las numerosas penas establecidas en las stipulatio. Albanese (1970) p. 70. 
truidos sobre la base de la poena, como composición de la venganza privada, impiden considerar su consecuencia como obligación. En principio, argumenta De Visscher ${ }^{35}$, la idea de la intransmisibilidad es ajena a la concepción jurídica de la obligación: la intransmisibilidad se explica exclusivamente porque la venganza recaía físicamente sobre el autor, quien debía pagar la suma de dinero, como mecanismo de composición y paz; el pago era así un medio de redención ${ }^{36}$. Del mismo modo, agrega, la noxalidad era ajena a toda idea de obligación, pues en esta subyacía siempre la idea de la venganza y no de la satisfacción de un interés ajeno ${ }^{37}$.

La categoría de la obligatio ex delicto, se debería a una elaboración posterior, propia de la jurisprudencia clásica. Según Betti, los veteres extrapolaron la situación del furtum flagrante. En este delito, siguiendo las explicaciones de Betti, el dañado siempre estaba autorizado para ejecutar directamente la manus iniectio sobre el autor del furtum, con el resultado de la esclavitud para último. Sin embargo, como se desprende del pasaje gayano 3, 189, los veteres admitieron que el autor del delito pudiese asumir idéntica posición del deudor adiudicatus, permitiendo al acreedor, la manus iniectio ejecutiva, cuya prisión era redimible. Agrega Betti que, aunque el delito no se considerara en esa época fuente de la obligacion, la manus iniectio ejecutiva representaría la estructura de la esclavitud primitiva, es decir, la esclavitud del deudor, sujeta a redención. Y, así como ocurrió con la obligatio ex contractu, la forma de prisión potencial en la que derivó la obligatio importó un estado primitivo de la sponsio, en el que la prisión fue efectiva. Sin poder precisar la época exacta, paulatinamente fue admitiéndose el pago de una compensación que, como argumenta el autor, representaba el precio del rescate, que derivó en el débito ${ }^{38}$.

De Visscher, por su parte, ha dedicado un largo estudio para explicar el origen de la obligatio ex delicto. El autor llama la atención en el tratamiento irregular que las Instituciones de Gayo dispensa a las fuentes de las obligaciones, puesto que luego de enunciar la división en obligaciones ex contractu y ex delicto $(3,88)$, sigue el tratamiento de las obligaciones contractuales (párrafos 89 a 162); la adquisición por intermedio de otro (163-168); modos de extinguir las obligaciones (solutio, novatio, acceptilatio, per aes et libram, párrafos 168-181), para detenerse, finalmente, en las obligaciones derivadas de delito (párrafos 182 y siguientes). La anomalía radica en que las obligaciones derivadas de delito son tratadas después de los modos de extinguir las obligaciones, como si las materias propias de las obligaciones, no se aplicaran a los delitos ${ }^{39}$. De Visscher descarta esta opción, pero ensaya una serie de argumentos que

\footnotetext{
35 De Visscher (1928) pp. 340; 343.

36 Es claro que el rasgo más característico de la evolución de los delitos se encuentra en el delito de damnum iniuria datum, regulado en el plebiscito aquiliano. Para esta cuestión, remitimos a nuestro trabajo, AEdo BARRENA (2009a) pp. 30-40. No obstante la discusión en cuanto a la naturaleza de la actio legis aquiliae, no debe pensarse que los caracteres penales desaparecieron con la evolución del Derecho romano. Por el contrario, muchos de ellos, como la intransmisibilidad, fueron descartados durante el ius commune y gracias a la labor de los canonistas. Véase, Arias Bonet (1988) pp. 209; 213. En el mismo sentido, véase Feenstra (1979) p. 46.

37 Sobre el sentido de noxa y noxalidad, véase Albanese (1970) pp. 70; 72.

38 Betтi (1955) p. 100. Véase también, Beтti (1962) p. 362, especialmente nota 1, la expresión obligari o obligare furti, noxias, etc., era una expresión radicalmente distinta de obligari ex delicto, pues la última significaba simplemente cometer o ser culpable de un delito.

39 Grosso (1961) p. 750, llama la atención sobre el tratamiento de la bipartición gayana, que relega el orden de los delitos como mero apéndice, en él las obligaciones ex delicto parecen como yuxtapuestas al esquema de las obligacines derivadas de contrato.
} 
permiten, en su concepto, una explicación histórica del orden, consecuencia de la posterior evolución de las obligaciones ex delicto. Entre otros que, con Gayo, aparece perfilada un nuevo orden que se superpone a las obligaciones ex contractu. Así Labeón, antes, había distinguido entre el actum (re, verbis) y el contractum. Gayo habría adoptado esta distinción, así como la ampliación de la noción del contractum y la incorporación de los delitos ${ }^{40}$.

El origen, no obstante, desde la perspectiva dogmática, operó, según Visscher, por una paulatina sustitución de la venganza privada por la composición que supuso la sanción pecuniaria (una redención del sujeto causante del ilícito). Ahora bien, las condiciones del ejercicio de la acción, destinada a la imposición de la poena, importaron un juicio (iudicium), que supuso la sustitución de la idea de la venganza por la relación obligatoria ${ }^{41}$. El juicio es compartido, desde otras perspectivas. Por ejemplo, Arangio-Ruiz, refiriéndose a la lex Aquilia, explicaba que con la actio legis aquiliae se sancionaba in simplum contra el que confesaba e in duplum si el autor del daño negaba su causación. Es lo que se conoce como la infitiatio. Hubo una especial penalidad al sujeto que negaba la realización del perjuicio. Este carácter de infitiatio era propio de las acciones mixtas, como ocurría precisamente con la lex Aquilia. Ahora bien, según el autor, el redoblamiento de la indemnización se considera un residuo histórico del régimen primitivo de la aprehensión corporal ${ }^{42}$.

Precisamente, la lex Aquilia es la que permite abonar argumentos en favor del origen contractual de la obligatio. La mayor parte de la doctrina está de acuerdo en que dicha acción tenía originariamente, un estricto carácter penal. Solo su evolución permitió incorporar paulatinamente, de modo progresivo, el carácter resarcitorio, aunque nunca dejará de ser un delito ${ }^{43-44}$. En este sentido, bien puede pensarse que la consideración de la obligatio

40 De Visscher (1928) pp. 345-355.

41 Afirma el autor: "La loi ayant par la suite imposé aux parties le devoir de composer, c'est-à-dire de racheter la vengeance, soit par voie d'accord privé, soit sous forme d'un arbitraje judiciaire, les actions cpnstituées en vue d'assurer ce rachat ont vu leurs conditions d'exercice tout naturellement déterminées par les principes régissant le droit de vengeance. C'est avec l'acceptation d l'action, du iudicium, que les parties pour la premiére fois entrent dans un rapport obligatoire: dès cet instant leurss relations cessent d'ètre régies par les príncipes du droit de vengeance pour ètre soumises aux règles ordinaires des obligations-types, c'est-à dire des obligations contractuelles. Une obligation pécuniaire s'est à cet instant même substituée au droit de vengeance”. DE VISSCHER (1928) p. 379.

42 Arangio-Ruiz (1945) p. 131.

43 Albanese agrega que la lex Aquilia: “...rapresenta un paso importantisimo verso il concepto di una pena risarcitoria: all'idea ormai prevalente di risarcimento, infatti, essa congiunge tenaci aspetti afflittivi”. Para Valditara, la evolución de la jurisprudencia en la valoración de los perjuicios, desde el valor del precio de mercado del bien hasta el criterio de la utilitas, mediante acciones in factum y terminando en el principio del id quod interest, producirá la modificación del carácter puramente penal de la acción aquiliana; así, la acción aquiliana no cesará su carácter penal desde el punto vista del régimen procesal, garantizando este mismo hecho el "mayor valor" con el que se gravaba al dañante, pero irá mutando su carácter como consecuencia de la evolución en la valoración de los perjuicios. ALbanese (1970) 63-64; 72 ss. Véase Valditara (1992) pp. 184 y ss. Ferrini ha argumentado de manera interesante con relación con el carácter penal originario de la acción. Sostiene que esta era otorgada al actual propietario y que aun cuando este dejaba de serlo, conservaba la acción, por cuanto esta tenía por objeto reintegrar la ofensa hecho al dominio violado y no simplemente reparar el daño económico causado. Ferrini (1930) pp. 192-193.

44 Con todo, no puede pasarse por alto, la amplia discusión sobre la materia. Otros autores, como Cannata, consideran que la acción tuvo carácter originariamente mixto, aunque otros estiman que dicho carácter se debió a la labor justinianea, véase CANnATa (1996) p. 10. Afirmando el carácter mixto, por todos ZimmermanN (1996) p. 970. 
ex delicto coincide plenamente con la paulatina despenalización del delito de damnum, el que, gracias a la labor jurisprudencial, fue adoptando cada vez más un carácter resarcitorio.

\section{b. El origen CONTRACTUAL DE LA OBLIGATIO}

\section{a) La sponsio como negocio que origina la obligatio}

En consecuencia, el origen primitivo de la obligatio se encuentra en el ámbito contractual. Betti cree que el sentido originario de la obligatio debe buscarse en el antiguo negocio de la sponsio, que importó la garantía en el cumplimiento de una expectativa del acreedor; el acto extintivo por excelencia, agrega, fue la solutio, en su forma originaria de solutio per aes et libram ${ }^{45}$. Como indica García Garrido, en efecto, una tesis entiende que la sponsio habría sido originariamente un negocio de caución. El sponsor no era el deudor, sino el garante de la satisfacción del deudor. Posteriormente, el verbo spondere y el sustantivo sponsio, se extendieron para reflejar el acto de vinculación al deudor ${ }^{46}$.

No obstante, debe indicarse que la opinión antes referida, dice relación con la función del pacto y no a su origen. Un sector importante de la romanística entiende que la sponsio tuvo origen religioso ${ }^{47}$. Desde este punto de vista, es decir, desde la concepción sacral de la sponsio, Talamanca arriba a una conclusión similar a la de Betti. En efecto, Talamanca sostiene que vas, praedes y sponsor (con independencia del problema relativo a su aparición cronológica), tuvieron la nota común el que el deudor no se comprometía personalmente de modo inmediato, pues el sometimiento parangonable a la esclavitud era potencial, pudiendo redimirse mediante la satisfaccion de la prestación. Ahora bien, según el autor, el carácter religioso de la sponsio, sirvió para espiritualizar la relación obligatoria, en términos que el estado de rehén, pasara a ser potencial ${ }^{48}$. Una opinión similar ha sustentado Pelloso, quien ha indicado que la obligatio primitiva supuso un vínculo material de heterogarantía, desarrollado a partir de la

\footnotetext{
45 Betti (1955) pp. 110-111; 113, quien indica que la misma voz contractus tuvo el significado originario de "adstringir"; de ahí que pueda deducirse, según Betti, que cuando los romanos utilizaron la voz contrahere, los negocios jurídicos fuentes de las obligaciones, fue el único modo que conocieron de crear el vínculo denominado obligatio. Coincide, Biondi (1962) p. 110.

46 García Garrido (2005) p. 256. Como explica Grosso: "Chè anche la sponsio debe aver tratto lo spunto dalla garanzia per il fatto di un terzo, per arrivare poi, attraverso la garanzia per il fatto proprio, alla essenzialità della promessa del fatto proprio, cui corrispondeva per un verso il principio che nemo factum alienum promittere potest $e$ per altro verso il carattere accessorio della promessa di garanzia". Grosso (1961) p. 752.

47 Por ejemplo, Ourliac y De Malafosse (1960) p. 94, consideran que tuvo un origen exclusivamente religioso. Véase, por todos, Talamanca, quien sostiene la siguiente opinión: “ $E$ diffusa in dottrina l'ipotesi che alle origini sponsio e stipulatio sarebbero diversi, poi confluiti nella verborum obligatio classica. La sponsio avrebbe un'origine religiosa; la stipulatio, invece, un'origine mágica (nel che ha giocato un ruolo la connessione di stipulari con stips, festuca di grano). Queste teorie no hanno, in effetti, alcun fundamento". Talamanca (1990) p. 560. Véase, también, Arias Ramos y Arias Bonet (1991) pp. 613-614, con la abundante bibliografía citada.

48 En relación con el origen religioso, estima Talamanca que un buen argumento para pensar de este modo, se encuentra en la propia etimología de la palabra: "Connesso con il greco 'spéndesthai' che ha un indubbio riferimento sacrale nell'ambito della semantica connessa con la libagione de in cui d'altra parte, si viene, con vicenda analoga, da identificare nelle 'spondai' un atto giuridicamente rilevante al livello del diritto internazionale e di guerra". TALAMANCA (1979) pp. 8-11.
} 
evolución de la sponsio (desde el carácter religioso a uno laico), que permitió comprender la sujeción como un vínculo potencial y no de sujeción material directa ${ }^{49}$.

Una perspectiva distinta ofrece, desde el procedimiento romano, Fuenteseca. Coincide la autora en que el origen de la obligatio se encuentra en la sponsio, es decir, en el ámbito contractual, pero estima que, desde una lectura procesal, se puede considerar de modo diverso a Betti, de Visscher y Talamanca, el contenido de la relación obligatoria. En efecto, como hemos visto, en opinión de estos autores, la obligación comprometía la persona física del deudor y el dinero equivalía a un precio del rescate. Paulatinamente, dicho compromiso transformaría la obligación en el vínculo entendido por los clásicos. En cambio, Fuenteseca estima que la legis actio per iudicis postulationem representó una innovación, al permitirse, a partir de las XII Tablas, la exigibilidad procesal de lo que hubiese sido estipulado. Agrega: "De la sponsio surge, por tanto, la noción de obligatio verbis clásica, que crea un vinculum iuris, sancionable con una actio in personam frente al obligatus (o debitor). Este vinculum iuris obliga al sujeto pasivo al cumplimiento del débito pecuniario, porque se trata de una obligatio pecuniaria, propia del creditum o contrato de crédito (pecunia stipulata). Frente al obligatus, el stipulator puede actuar in iure mediante una actio in personam. Por tanto, en contra de la opinión de Betti y según lo expuesto hasta aqui, la concepción de la obligatio como vinculum iuris surge en la esfera procesal desde el momento en que la sponsio se puede hacer efectiva a través de una actio in personam, mediante la cual exigía el cumplimiento del dare facere oportere prometido en la misma" ${ }^{50}$.

En una línea similar argumenta Cannata. Para este, la obligatio tuvo su origen también en la sponsio y, desde el punto de vista del procedimiento, en la actio per iudicis postularionem y, en consecuencia, con Betti, Talamanca y De Visscher, afirma que la sujeción personal no coincidió, ni debe confundirse, con la relación emanada de la obligatio, pero a diferencia de estos autores, en su concepto, la obligatio debió haber sido introducida, necesariamente por los Pontífices, hacia el 500 a.c., puesto que aparecía regulada en la XII Tablas, pero, agrega el autor, el nuevo procedimiento de la actio per iudicis postulationem no vino a derogar el sistema de sujeción personal emanado de la manus iniectio procesal o extraproceso. Ahora bien, para Cannata, las mismas razones económicas permitieron la paulatina asimilación de la sujeción personal a la relación obligatoria, cuya muestra más significativa vino a estar representada por la sustitución de la vindicta por la poena pecuniaria, que permitirá considerar, ya con Gayo, el delito como fuente de la obligación ${ }^{51}$.

\section{b) El nexum como origen de la obligatio}

En relación con el nexum, se sabe que se trata de un arcaico negocio, que ha llegado hasta nuestros días por referencias imprecisas. La única fuente jurídica, fuera de discusión, se encuentra en las XII Tablas, VI.1: "cum nexum faciet mancipiumve, uti lingua nuncupassit ita jus esto" 52 . Es por eso que Noailles, considera que se trata de uno de los más grandes

\footnotetext{
49 Pelloso (2011) pp. 188-194.

50 Fuenteseca Degeneffe (2008) p. 235. Como indica Fuenteseca, la legis actio per iudicis arbitrive postulationem significó la apertura de una vía procesal para la economía pecuniaria desde las XII Tablas, porque así lo exigía el tráfico de los bienes de cambio. Afirma que la revolución económica se tradujo en una nueva concepción del ius, concebido ahora como deber jurídico. Fuenteseca (2001) p. 465.

51 Cannata (2003) pp. 63 y ss.

52 Las otras referencias son indirectas. Varron se refiere al nexum, citando a Quinto Mucio Scevola y a Manlio.
} 
problemas del Derecho romano, su crux maxima ${ }^{53}$, y, desde luego, de acuerdo al modo en que se conciba, se le podrá considerar origen de la obligatio ${ }^{54}$. Veamos algunas opiniones en este sentido.

Talamanca considera que el nexum no pudo constituir el acto que originó la obligatio. Estima, como se ha indicado supra, que el nexum importó la esclavitud inmediata del nexi y, desde este punto de vista, no pudo suponer la creación de la obligatio, cuyo sometimiento personal quedaba sujeto a la no satisfacción de la expectativa del acreedor. Argumenta en autor que, como cualquier acto per aes et libram, no pudo estar sujeto a condición. Por último, sostiene, el nexum necesariamente debió haber surgido en un momento en el que ya se conocía la aes rude y, en consecuencia, no resulta sostenible que el desarrollo social y económico no hubiese permitido la aparición de la idea de la obligación ${ }^{55}$. Este último argumento es especialmente compartido por Pelloso ${ }^{56}$.

Desde una perspectiva similar a Talamanca, arribará a la conclusión opuesta, Pugliese. Efectivamente Pugliese considera -a diferencia de Betti-, que el nexum consideraba la creación de un vínculo corporal del sujeto deudor, para el caso que no se cumpliera la prestación acordada. Por el contrario, el cumplimiento del nexi no bastaba para la liberación del deudor,

53 Noailles (1940-1941) p. 206. Sobre las dificultades para arrojar luz sobre la institución, véase también la concisa explicación de Grosso (2001) pp. 510-511.

54 No podemos detenernos ni en la amplia bibliografía que trata el nexum, ni en las numerosas corrientes que lo explican. Claramente, al menos pueden concebirse tres corrientes. La más difundida entiende que el nexum fue un contrato destinado a la creación de una obligación. El nexum sería un préstamo formal, por el cual una persona quedaba obligada a la entrega de una cierta cantidad. La fórmula nuncupatio revelaría el empleo de una frase solemne que vinculaba al deudor (como ocurría con la mancipatio); en consecuencia, el incumplimiento de la obligación generada otorgaba una manus iniectio para disponer de la persona del deudor. Es la tesis sustentada por Huschke (1846), Disponible en <http://reader.digitale-sammlungen.de/de/fs1/object/ display/bsb10565630_00015.html (fecha de la consulta: 2 de marzo de 2013) >. Con arreglo a la segunda tesis, el nexum no fue un contrato de préstamo, sino un acto solemne de pignoración del propio deudor; no como consecuencia del incumplimiento de un contrato, sino que se trataba de individuos dados en prenda al acreedor. Se estaba en presencia, en consecuencia, de una sujeción personal del deudor. La manus iniectio sería consecuencia del ejercicio de la actio in personam. Entre la manualística, por todos, Arangio-Ruiz (1986); BONFANTE (1959). La tercera corriente constituye una variación de la segunda. Varios autores consideran que, en efecto, el nexum supuso, simplemente, la sujeción personal de la persona del deudor. Talamanca, estima que, cualquier fuese la estructura jurídica del nexum, este supuso la esclavitud inmediata del nexi frente al acreedor. Según Talamanca, para la mentalidad predecenviral, la única posibilidad era el sometimiento inmediato de la misma persona del deudor; en cambio, estima que resulta más dudoso que el nexum importara esclavitud solo a condición del incumplimiento de la obligación, véase TAlamanca (1979) p. 6. En términos similares se expresa García Garrido, que considera el nexum un acto destinado al sometimiento de una persona, en garantía de una deuda propia o ajena, véase García Garrido (2005) p. 207. En esta línea, destaca la tesis de Betti, según el autor, el nexum fue un acto en virtud del cual el deudor y las personas sujetas bajo su potestad, quedaban adscritos a prestar servicios en favor del acreedor, para la satisfacción de una deuda no cumplida. Para Betti, el nexum cumplió el papel análogo a la mancipatio hecha a título de fiducia, con el objeto de garantizar el cumplimiento de una obligación (lo que permitía al acreedor el uso y goce de la cosa); de la misma forma, el nexum constituyó el acto de autopignoración del deudor, que garantizaba de ordinario un mutuo. La diferencia fundamental, sin embargo, entre la mancipatio fiduciaria y el nexum se encontraba en la forma de extinción. Mientras el primero suponía la remancipatio del paterfamilias, el nexum se extinguía en virtud de la solutio per aes et libram, es decir, un autorrescate del deudor, véase BetTi (1955) pp. 157-161.

55 Talamanca (1979) pp. 6-7.

56 Pelloso (2011) pp. 183-185; cree que el nexum no tuvo ningún papel en el origen de la obligatio. 
que exigía la celebración de un acto formal y distinto: la solutio per aes et libram ${ }^{57}$. Peppe ha entendido, de modo similar a Betti, que la addictio, que era una sanción, no pudo impotar el trabajo del deudor y, en este sentido, rechaza la idea del autorrescate, toda vez que no estamos en presencia de una ejecución patrimonial, sino que de una sanción corporal ${ }^{58}$.

Una opinión diversa se encontrará en Betti, quien sostiene que la obligación excontractu originaria, podía generarse en virtud de la antigua sponsio, cuya garantía supuso el sometimiento del deudor, frente a la insatisfacción de la prestación, a la actio in personam ejecutiva. El deudor garantizaba con su persona (estrictamente, con su trabajo por un determinado tiempo), bien el incumplimiento de un mutuo de dinero, bien por la comisión de un delito, restando toda eficacia ejecutiva a la figura, pues, para Betti, el nexum no importó la manus iniectio. Como dice el autor: "Per un orecchio romano parlare di «nexum" coattivo sarebbe una stridente contraddizione in termini, que urterebbe contro la manifesta spontaneità del "nexum se dare», "nexum inire»". Precisamente, las diferencias estructurales entre sponsio y nexum suponen también sus diferencias en la forma de obligarse: el sponsio se sujetaba a una responsabilidad perentoria, mientras que el nexi asumía una responsabilidad indeterminada en el tiempo, que solo se extingue con el completo cumplimiento de la prestación insatisfecha, mediante el trabajo que realiza en favor de acreedor. En cualquier caso, para Betti, la primitiva responsabilidad derivada de un contrato, en cualquiera de sus formas antiguas (sponsio o nexum), resultaba en una prisión, como consecuencia de una garantía voluntaria que el sui iuris prestaba de manera actual o potencial. La evolución hasta el período clásico, habría permitido la transformación desde una prisión efectiva, a una ideal; y, correlativamente, de una garantía corporal a una puramente personal ${ }^{59}$.

\section{c) El desarrollo de la idea técnica de contractus como origen de la obligatio: la tesis} de Gaudement

Una mirada distinta, que en cierto modo escapa de los rígidos moldes de la opción entre el origen delictivo y contractual de la obligatio. Gaudement, a nuestro juicio, ofrece una particular mirada. En efecto, Gaudement ha propuesto que el origen y desarrollo de la obligación supuso un sucesivo proceso de abstracción, que arranca de una antigua distinción entre nexum y mancipatio, es decir, que desde temprano se estableció la distinción entre el acto generador de obligaciones y otro, la mancipatio, con efecto real (distinción que en definitiva recogerá la definición de Paulo, que analizaremos) ${ }^{60}$. Para Gaudement, hay que vincular el origen del concepto técnico de obligatio, con el de contractus, sustantivo desconocido en su sentido técnico-jurídico hasta la primera mitad del siglo I a.c. (a diferencia de la expresión contrahere); de hecho, Gaudement indica que Quinto Mucio Scaevola no empleó en sus 18 libros del Derecho civil, el término ${ }^{61}$. La voz contractus aparece con

\footnotetext{
57 Pugliese (1991) p. 145.

58 Peppe (2009) p. 143.

59 Betti (1955) pp. 158-159; 164.

60 Por eso, Jörs y Kunkel, entienden que la stipulatio fue un contrato de derecho civil, fuente de las obligaciones, con efecto puramente obligacional, a diferencia de la mancipatio y de la in iure cessio. Jörs y KUnKEL (1965) pp. 137 y ss.

${ }_{61}$ Gaudement (2001) p. 144. En efecto, siguiendo a Schulz (1960) p. 445: “El verbo contrahere es un verbo
} 
Servio Sulpicio Rufo, cuya opinión se encuentra en un pasaje de Aulio Gelio (4, 4, 1-2) ${ }^{62}$, aparece vinculada con este jurista a la stipulatio y la sponsio. Según Gaudement, la expresión no alcanza todavía un significado preciso, puesto que aparece vinculada a figuras que, en estricto rigor, son actos jurídicos unilaterales. Aun así, la labor de la jurisprudencia conducirá a estimar la el contrato como el encuentro entre dos manifestaciones de la voluntad ${ }^{63}$.

Un último eslabón se encuentra en Labeón, primer jurista que empleará la expresión obligatio, relacionada con el contractus. Ahora bien, en el pasaje, Labeón, contenido en D., $50,16,19^{64}$, hace equivalente el término de contrato, con el synallagma griego ${ }^{65}$. Gaudement ensaya una hipótesis de cómo el término llegó hasta el jurista. Sin duda, la expresión fue tomada de Aristóteles. Ahora bien, en el tiempo en que se supone la influencia de la filosofía griega en la cultura romana, las obras de Aristóteles se encontraban disponibles en Roma. Para Gaudement, Cicerón poseía dichas obras y este, a su vez, era íntimo amigo de Trebacio, maestro de Labeón. Resulta entonces una explicación plausible para la adopción de un concepto propio de la filosofía griega, que condujo a la creación de una categoría general $^{66}$. Por último, Gaudement considera que el escenario estaba maduro para considerar,

antiguo y fue usado literal y metafóricamente (Thes. L.L., 757 y s., 764). Usado metafóricamente, contrahere significa, por regla general (Voc. Iud. Rom. I, 1.001) "realizar», "perpetrar", "concitar» (admittere, committere, constituere): contrahere invidiam, offensionem, amicitiam, inimicitas, culpam, crimen, stuprum, incestum, aes alienum, societatem, nuptias, etc. Los autores deben guardarse mucho de creer que en la lengua latina, la palabra contrahere significa primariamente "celebrar un contrato". Los mismos juristas clásicos, usaban contrahere en el amplio sentido antes hemos indicado. Algunos de los textos más importantes son espurios, pero cuando Gayo (Inst. 2.14) dice: "Incorporales res sunt quae tangi non possunt qualia sunt... obligationes quoquo modo contractae», indudablemente está pesando tanto en las obligaciones ex delicto como en aquellas que nacen ex contractus. En contraste con el verbo contrahere, el sustantivo contractus apareció mucho más tarde (Thes. L.L. IV 753 y s.) No se remonta más allá de la época de Cicerón. Se halla ausente en las obras de César, Cicerón, Salustio, Livio, Tácito, Suetonio y los Plinios (maior y minor)... ”. Véase también, en el mismo sentido, Grosso (1961) p. 751.

62 Dice el pasaje, textualmente: "contractus stipulationem sponsionumque, qui dicebatur sponsalia".

63 Gaudement (2001) pp. 144-145; 149.

64 Labeón es citado, en sus comentarios al Edicto, por Ulpiano. Según el pasaje: "Labeo libro primo Praetori urbani definit, quod quaedam agantur, quaedam gerantur, quaedam contrahantur. Et actum quidem generale verbum ese, sive verbis, sive re quid agatur, ut in stipulatione, vel numeratione, contractum autem ultro citroque obligatio-

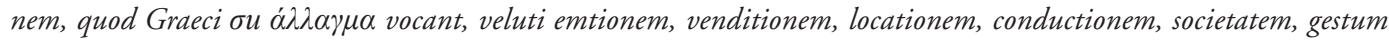
rem significare sine verbis factam" ("Labeón define en el libro primero del Pretor urbano, que unas cosas se hacen, otras se gestionan, y otras se contratan. Y ciertamente que la palabra acto es general, ya sea que alguna cosa se haga de palabra, ya sea que realmente, como en la estipulación, o en la entrega de cantidad; pero contrato significa obligación

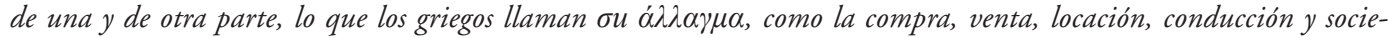
dad; gestionado significa cosa hecha con palabras").

65 Como indica De los Mozos (1994) pp. 110-111, Labeón entiende que el contrahere proviene de una actuación conjunta (ultro citroque) y como no había un nombre en el latín jurídico para dicho fenómeno, se empleó la expresión griega del synallagma, que significaba contrato en sentido amplio y no exclusivamente contrato bilateral. Con todo, en el Libro V, Cap. II de la Ética a Nicómaco, Aristóteles habla del synallagmáta, tanto para referirse a los actos voluntarios, como involuntarios. Llama actos voluntarios a la venta, la compra, el préstamo de cosas, fianza prestada por otro, comodato, depósito, prestación. El origen de esa prestación es, según Aristóteles, voluntario. El cuanto a los actos involuntarios, Aristóteles incluye varios delitos, como el asesinato, el falso testimonio, el encarcelamiento, robo con violación, mutilación, abuso, insulto, etc. Véase, Martini, (2009) pp. 68 y ss.

${ }^{66}$ Gaudement (2001) pp. 145-146. En D. 2, 14, 7, 2, Ulpiano indica: "Sed et si in alium contractum res non transeat, subsit tamen causa, eleganter Aristo Celso respondit, ese obligationem; utputa dedi tibi rem, ut mihi aliam

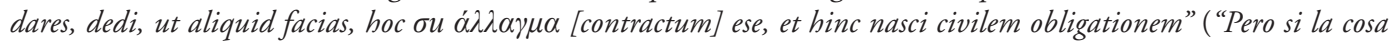


ahora, el contrato -en tanto categoría general-, como fuente de la obligatio. Particularmente, Gaudement destaca el pasaje del D. 2, 14, 7, 2, en el que Ulpiano, en sus comentarios al Edicto, libro IV, cita la opinión del jurista Aristón ${ }^{67}$.

\section{d) La tesis ecléctica de Pugliese}

Más lejos ha ido Pugliese. Para este autor, diversas instituciones contemplaron la sujeción personal de un sujeto a otro, tanto en el ámbito contractual, como a propósito de los delitos: en unos casos, dicho régimen de sujeción era inmediato, directo (como en el furtum flagrante); en otros fue virtual, dependiendo de la satisfacción del propio deudor o de un tercero (como ocurrió con el nexum, vades, praedes o la misma sponsio). Sin embargo, admitida esta pluralidad de vínculos a la hora de configurar la obligatio clásica, reconoce que la sponsio fue capaz de perfilar la obligatio en los períodos sucesivos y de incorporar en la noción los delitos (debido al rol que esta jugaba en ellos): "Tuttavia, mentre la soggezione alla pena corporale, il vincolo da "nexum», l'asservimento dei "vades» e dei "praedes» apparvero in un certo momento sotorico semplici rami secchi e finirono per sparire, invece il vincolo da «sponsio» e quello che gravava sui colpavoli di certi delitti, su puniti con pena pecuniaria, trapassarono, pienamente vitali, nel periodo preclassico e classico e costituirono il nucleo delle "obligationes" di questo periodo. Si può anzi dire che essi era già senz'altro "obligationes», anche se ai tempi delle XII tavole non resulta che abbiamo recivuto questo nome". Agrega Pugliese que: "Cosi il vincolo da sponsio venne ad esere la prima genuina "obligatio", che, per quanto chi consta, i Romano abbiamo conosciuto" 68.

\section{EL CONCEPTO DE LA OBLIGATIO CLÁSICA: REMEDIOS FRENTE AL INCUMPLIMIENTO}

\section{A. LAS DEFINICIONES DE LA OBLIGATIO ROMANA}

Llegados a este punto, podemos referirnos al concepto clásico de la obligatio, tal como termina perfilándose. Como apunta Dumont, el sustantivo al que hacemos mención deriva de un verbo que supone conducta activa. Obligatio es, en este sentido, el acto de atar, más que encontrarse atado ${ }^{69}$. Otros términos jurídicos propios del Derecho romano

no pasare a otro contrato, y subsistiere, sin embargo, la causa, respondió acertadamente Aristón a Celso, que habia obligación; por ejemplo, te di una cosa, para que me dieras otra; di, para que hagas algo, esto es $\sigma u$ á $\lambda \lambda \alpha \gamma \mu \alpha$ [contrato], $y$ de aqui nace una obligación civil").

67 Gaudement (2001) p. 147. De los Mozos (1994) pp. 112; 114-116, avanza la hipótesis de que fue Gayo quien incluirá el uso técnico de la expresión contractus. Según el autor, la summa divisio gayana no significó el uso de contractus en un sentido amplio, como todo acto lícito fuente de la obligación. La utilización del contrato en sentido técnico, frente a otras formas de obligarse, quedaría muy clara en algunos pasajes. Cita el autor en particular G. 3, 91. Para De los Mozos: "Esta argumentación -la del pasaje citado- es indicativa de que el contrato ha pasado a primer plano en el terreno de la condictio y de las obligaciones que se contraen re, ahora es el modelo, el modo natural de obligarse". El carácter estricto del contrato, quedaría perfilado, finalmente, en la Res cottidianae, D. 44, 7, 1pr., pasaje en el Gayo reconoce, junto a los delitos y los contratos, varias causas que generan la obligación.

68 Pugliese (1991) pp. 141-143; 148; 505.

69 Dumont (1963) p. 79. Que no es otra cosa que describir un vínculo físico; del sustantivo: ligo (yo ato); $o b$ (alrededor del cuerpo). Véase, Ourliac y De Malafosse (1960) p. 23. 
también revelaron este carácter activo: damnum, sustantivo utilizado en el capítulo tercero de la lex Aquilia, por ejemplo, significó primitivamente acto de lesionar (damnum facere), antes que la recepción del daño por la víctima (damnum dare $)^{70}$. En suma, como indica Rodríguez Ennes, el verbo (y consecuentemente el sustantivo), en el lenguaje jurídico, tenía un sentido propio de la acción: físicamente, atar una cosa o dar en garantía; in personam, imponer un deber a alguien ${ }^{71}$.

Pero su evolución permite apreciar que, el sentido activo del verbo y del sustantivo correlativo se modificará en la medida que el vínculo se transforma en otro ideal y, consecuentemente, patrimonial: del acto de sujeción a la situación del deudor, frente a la expectativa del acreedor ${ }^{72}$. Por ello, no puede desconocerse entre los juristas romanos la paulatina asimilación de conceptos generales ${ }^{73}$. Desde esta perspectiva, la obligatio reagrupó, ya en la época clásica, bajo un mismo nombre, los mismos efectos derivados de delito y contratos, independientemente de la modalidad del acto que daba lugar a la obligatio, pues como informa Pieri, la derivación al sustantivo "tio" revelaba la noción abstracta de procesos ${ }^{74}$. Ha de seguirse en este punto, en consecuencia, el razonamiento de Scherillo, quien analizando algunos pasajes de Gayo (3, 88, que establece la división de las fuentes; y, 2, 14), llega a concluir que el empleo del sustantivo tanto en plural, como en singular, lo que revelaría, a su juicio, la abstracción que supuso el concepto ${ }^{75}$.

Contamos con dos famosas definiciones, una, de Paulo y otra de Justiniano. Según Paulo, D. 44, 7, 3pr.: "obligationum substantia non in eo consistit, ut aliquod corpus nostrum aut servitutem nostram faciat, sed ut alium nobis obstringat ad dandum aliquid vel faciendum vel praestandum". Y, en la conocida definición de Justiniano 3, 13pr.: "obligatio est iuris vinculum, quo necessitate adstringimur alicuius solvendae rei secundum nostrae civitate iura". La bibliografía y las discusiones sobre dichas definiciones son cuantiosas y no constituyen el objeto de nuestra investigación ${ }^{76}$. Sin embargo, será necesario referirse brevemente a ellas para nuestra reflexión posterior.

\footnotetext{
70 Para esta cuestión, véase nuestro trabajo Aedo Barrena (2009b) p. 325. Como indica Kelly (1964) p. 73, la palabra damnum deriva de la raíz damenon, que significaba dar.

71 Rodríguez EnNes (2011) p. 693.

72 En este sentido se pronuncia también, Dumont (1963) p. 79.

73 A menudo la romanística moderna discute sobre el carácter de la jurisprudencia clásica, desde la perspectiva metodológica, comparada con la bizantina. Se estima que la jurisprudencia clásica fue exclusivamente casuística, mientras que la bizantina, por oposición, amaba los conceptos generales y abstractos. En este sentido, es cierto, como indica García Garrido (2005) p. 24, que los juristas romanos desarrollaron una dogmática jurídica, ni una doctrina que no fuera encaminada inmediatamente a la práctica. Aun así, como afirma MACCormack (1972) pp. 127 y ss., ello no debe conducir a pensar que los clásicos no formularan reglas o generalizaciones; así como el argumento de que los compiladores amaban los conceptos abstractos, tampoco prueba que aplicaran reglas o definiciones desconocidas por los clásicos, sino que al contrario. El problema metodológico ha preocupado desde hace bastante tiempo a los romanistas modernos, desde las críticas a la metodología interpolacionista, hasta la búsqueda de nuevas aproximaciones al trabajo compilatorio del Digesto. Una excelente exposición de este problema puede encontrarse en LAzo (2004).

74 Pieri (1990) p. 227.

75 Scherillo (1971) p. 103.

76 Véase, por todos, Lantella (1971) pp. 167 y ss.
} 
En la definición de Paulo, se pone énfasis en la distinción entre la obligatio y el ius corporal. En la obligatio, la satisfacción del interés tutelado viene dada por la actividad del deudor; en cambio, en el derecho real, la satisfacción se produce por la actividad del propio titular $^{77}$. Más que una definición, como advierte Cannata, Paulo está destacando simplemente que la obligatio no ofrece al sujeto activo un poder sobre una cosa, sino de crear una relación entre dos sujetos determinados; uno, el obligatus, gravado con un deber jurídico (concretamente, de prestación $)^{78}$.

En relación con la definición de Justiniano, se ha radicado el problema en el origen de la definición, Scherillo considera que la expresión “iuris vinculum quo necessitate adstringimur", pudo haber sido tomada de Gayo 3, 87, pasaje en el que, a propósito de la in iure cesio hereditaria, emplea la expresión "iuris necessitate hereditati adstringimur"79. Para Talamanca, sin duda alguna se trata de un texto clásico, porque, de otra forma, carece de sentido la remisión, en época imperial avanzada, al ius civile; sin embargo, no cree que pueda aceptarse la tesis de Scherillo, en orden a que su origen se encuentre en Gayo ${ }^{80}$. Por lo que toca a aliquid solvendae rei, Guarino ha defendido la tesis de que la definición, siendo clásica, se encuentra incompleta, pues la frase hay que leerla como solvere rem, en otros términos, que solo se habría referido a un tipo de obligación (la de dar, excluyendo las de hacer y no hacer $)^{81}$. En todo caso, siguiendo a Pelloso, la definición permite excluir cualquier referencia directa al acreedor. Para el autor, el objeto del vínculo es exclusivamente el deudor, un vínculo-ligatio en el que se adstringe al sujeto pasivo a satisfacer ${ }^{82}$. La referencia al Derecho civil ("secundum nostrae civitatis iura") ha sido discutida, en términos de que alguno la considera como una referencia solo al ius civile, mientras que otros entienden que comprende también el ius honorarium ${ }^{83}$.

\footnotetext{
77 Scherillo ha hecho un esfuerzo por comprobar, en sustancia, la clasicidad de la definición de Paulo, comparándola y cotejándola con un conjunto armónico de textos, entre ellos D. 4, 7 3, 1, del propio Paulo o el de Gayo 4, 3. En relación con el primer pasaje, Scherillo advierte que Paulo emplea una sistemática idéntica a la que utilizará Gayo, en sus instituciones, con lo que se deduce que la voz obligatio revelaba una categoría jurídica conocida por los juristas romanos. En cuanto al pasaje gayano antes citado, Scherillo piensa que la expresión aut servitutem nostram es una abreviación de un texto más largo de Paulo, apareciendo en Gayo nuevamente la contraposición corpora y ius. SCHERILLo (1971) pp. 103-107.

78 Cannata (2003) cit., pp. 14-15.

79 Scherillo (1971) p. 109. Para Pelloso la primera parte del concepto contiene un género (vinculum), que aparece primero en la definición, seguida de una especie que lo identifica (el carácter de iuris) y puntualizado, agrega, con el reclamo pleonástico de la necessitas de solvere. Por ello, Pelloso entiende que la definición enfatiza que lo propio del vínculo es la juridicidad, entendida como un instrumento procesal que favorece al acreedor. Pelloso (2011) pp. 222-225.

80 Talamanca (1979) pp. 18-19. Le sigue, Guarino (2011) p. 348.

81 Véase Guarino (1997) p. 803. Con todo, en Guarino (2011) pp. 351-352, ha expresado la opinión de que la frase "necessitas alicuis solvendae rei», no puede ser traducida con el significado de solvere, con el sentido de pagar; y res, en el sentido de cosa, bien un objeto. Por el contrario, ahora Guarino cree que dicha frase expresa la sujeción o sumisión del deudor al acreedor, en orden al cumplimiento de un determinado asunto.

82 Pelloso (2011) pp. 229-231.

83 Véase, Lantella (1971) pp. 172-173, nota 9. No solo eso. Por ejemplo, Biscardi entiende que el pasaje está interpolado, destinado a excluir del ámbito de aplicación, las obligaciones naturales, véase Biscardi (1994) pp. 26 y ss. Rechaza esta conclusión, Guarino (2011) p. 350.
} 


\section{B. ¿Gozó El ACREEdor de UN VERDAdERo DERECHO SUbJETIVO DE CRÉdito?}

Ambas definiciones, en cualquier caso, describen la obligatio, ahora, como una relación idealizada, que pone al deudor en la necesidad de satisfacer una prestación; y, al acreedor, le dota de un verdadero ius para obtener la satisfacción de dicha prestación (precisamente, el texto de Paulo, refiere la contraposición entre la res corporalis del ius propio de la obligatio). Pero, nuevamente, dos cuestiones deben considerarse para valorar adecuadamente lo que acaba de escribirse. La primera es explicar, exactamente, la idea del derecho subjetivo o potestad del acreedor en la obligatio romana; lo segundo, examinar el alcance de dicha potestad ${ }^{84}$.

En cuanto a lo primero, es decir, la existencia del poder o derecho del acreedor, debemos necesariamente reflexionar, aun cuando brevemente, sobre el derecho subjetivo del acreedor y plantearse la pregunta, precisamente, en términos interrogativos, ¿tuvo el acreedor en Roma un genuino derecho subjetivo? Cómo apunte metodológico, siguiendo a Guzmán Brito, la cuestión no consiste en decidir si los juristas romanos reconocieron los poderes o facultades de un sujeto. Lo decisivo, en su concepto, es que se hayan designado dichas facultades o poderes como derecho. Desde esta perspectiva, Guzmán Brito advierte que las fuentes tienen múltiples referencias a potestas o facultades, pero, añade, en ninguna de ellas se las califica como $i u s^{85}$. En un sentido similar, Gioffredi ${ }^{86}$ ha argumentado que la expresión ius, en el sentido subjetivo con el que se le empleaba en el Derecho romano, podía significar: a) esfera jurídica, condición o posición jurídica; b) prerrogativa, atribución, facultad, título. Con todo, el autor, no ha podido encontrar en el análisis de estos sentidos, alguna materia relativa a la obligación; en otros términos, que la posición del acreedor fuera calificada de $i u s^{87}$, ni en los textos del Digesto, ni en Gayo, ni tampoco en Justiniano.

En verdad, como advierte d'Ors, la expresión ius tiene un sentido único, intermedio entre norma y facultad: "que es precisamente, el de "posición justa»". Agrega el autor: "Como es sabido, el empleo del ius est resulta de un empleo antiquísimo, en paralelismo al fas est, sin

\footnotetext{
${ }^{84}$ La expresión "potestad", que ocupamos, en caso alguno se relaciona con el lenguaje técnico empleado en Roma. Para el uso de la expresión en el Derecho romano, referimos a Hernández Tejeiro (1946) pp. 622 y ss. Como explica el autor, en el Derecho romano, la expresión decía relación con el poder de actuación del magistrado.

85 GuzMán Brito (2003) p. 407.

86 Gioffredi (1967) pp. 231-235.

${ }^{87}$ En el Digesto, al abordarse el significado de ius, no se lo identifica con el denominado derecho subjetivo. En efecto, en D. 1, 2, 11 pr., Paulo dice: "Ius pluribus modis dicitur. Uno modo, quum id, quod semper aequum ac bonum est, ius dicitur, ut est ius naturalle; altero modo, quod omnibus aut pluribus in quaque civitate utile est, ut est ius civile; nec minus ius recte apellatur in civitate nostra ius honorarium. Praetor quoque ius reddere dicitur, etiam quum inique decernit, relatione scilicet facta non ad id, quod ita Praetor fecit, sed ad illud, quod Praetorem facere convenit. Alia significatione ius dicitur locus, in quo ius redditur, apellatioen collata ab eo, quod fit, in eo, ubi fit; quem locum determinare hoc modo possumus: ubicumque Praetor salva maiestate imperii sui salvoque more maiorum ius dicere constituit, is locus recte ius apellatur". En cualquier caso, léase el pasaje con la prevención de Villey (1976) p. 33, quien entiende que las nociones del ius recopiladas en el Digesto, como la de Paulo, que comentamos, trasuntan la filosofía griega, correspondiendo sus definiciones más a la palabra griega dikaion que a la concepción de ius. En cualquier caso, está de acuerdo que en este tratamiento de las primeras partes del Digesto, la palabra ius no significa nunca derecho subjetivo: “...Pues el Digesto, relativamente parco en este punto, se limita a sugerir la significación esencial de la palabra ius (lo justo, el objeto de la Justicia, aquello que encuentra su fuente en la naturaleza, las leyes civiles, el edicto del pretor o los tribunales), y, después, un pequeño número de sentidos derivados (el Arte de los justo, el lugar en donde se pronuncia lo justo, accesoriamente, el vínculo de parentesco)".
} 
que tengamos que entrar ahora en la cuestión de la distinción entre ius y fas, que nos alargaría excesivamente este artículo. Ahora bien: ius est no quiere decir, evidentemente, ni "hay facultad" ni "hay norma", sino más bien "es justo" o "es una posición justa»". No obstante, como advierte, la distinción entre titularidad y normatividad, impropia de la mentalidad romana, se hizo posible gracias al monopolio por el emperador. El ius deja de ser una disposición privada y posibilita la aparición del Derecho objetivo, surgiendo en época postclásica la idea de ius como derecho subjetivo ${ }^{88}$.

Villey, por su parte, ha hecho notar, entre los textos de Gayo, que la expresión ius no se refería únicamente a la facultad o potestad. Pone, como ejemplo, los pasajes gayanos 2, 12 y ss., en el que se enumeran diversas especies de iura (ius eundi, o derecho de pasar; stillicidium avertendi (de desviar las aguas lluvias), entre otros). Pero agrega Villey que también ius refiere situaciones negativas: ius non altius tollendi (derecho de no sobre-elevar), stillicidium non avertendi (derecho de no desviar aguas lluvias); en suma, que la expresión ius -traducida como derecho por comodidad-, refiere también a cargas. Ahora bien, en el plano sustantivo, Villey entiende que la jurisprudencia romana, fuertemente influida por la filosofía griega, no articulaba el estudio de las materias en función de los derechos de las personas. La jurisprudencia, por el contrario, tenía por objeto el estudio de las cosas y la condición de cada cosa en un mundo ordenado, es decir, el estatuto o condición de cada $\operatorname{cosa}^{89}$.

En particular, respecto del tratamiento gayano, Villey expresa la acertada opinión de que la palabra iura, en la partición gayana de cosas, equivale a cosas incorporales. En efecto, habrá que recordar que, entre las cosas, Gayo distingue las privatas y las publicae, y, dentro de las primeras, las corporales e incorporales (servitutes, ususfructus, hereditas, obligatio). Para Villey, Gayo recoge una tradición jurídica que deja sentir su influencia de la filosofía griega. Frente a las cosas corporales (corpóreas, materiales), el jurista ubica aquellas que son creadas por el Derecho y que existen, podríamos decir, idealmente. Por ello, en Gayo, obligatio y ius obligationis, según Villey, significan lo mismo. El ius obligationis, al que expresamente hace referencia Gayo D. 1, 8, 1, 2, no representaba el derecho de crédito. Por el contrario, la obligatio era una cosa objetiva: un vínculo particularmente contraído ${ }^{90}$.

Santoro hace la interesante observación de que la relación obligatoria hacía referencia al deudor. Agrega que esporádicamente, como en los pasajes del D. 4.2.13, D. 48.7.7; D. 4.2.12.2 o D. 20.6.5.2 y Gayo 2, 14, se usa la ius obligationes, pero agrega que se emplea en el sentido de indicar que la obligatio era una res incorporalis, es decir, una entidad jurídica ${ }^{91}$.

\footnotetext{
88 D’Ors (1953) pp. 295-297. Profundiza estos argumentos en D’Ors (1954) pp. 635-640. Una opinión similar sostiene Cesarini (1968) pp. 663-665. El ius romano no podía identificarse enteramente con el conjunto normativo (dada la profusa fuente normativa romana), ni con la subjetividad del poder de un sujeto frente a otro. Cesarini la denomina, la unidad dinámica de la subjetividad y la objetividad, caracterizada por la famosa definición de la justicia. El ius es así el poder de un sujeto y la tipicidad de la situación práctica determinada.

89 Villey (1976) pp. 36; 42. La verdad es que toda esta discusión obedece a una de carácter más general, pues dice relación con la influencia de la filosofía griega sobre el Derecho romano y las decisiones de los jurisconsultos romanos. Sobre esta materia, la bibliografía es muy amplia y no podemos detenernos en ella, pero puede consultarse a Reinoso (1988) pp. 1026 y ss.

90 Villey (1976) pp. 77, 85; 88-90.

91 Santoro (2001) p. 260, nota 14.
} 
Robleda, por el contrario, ha sostenido que la idea de derecho subjetivo puede encontrarse en Gayo. Varios pasajes de las Instituciones le permiten pensar así, referidos a las relaciones de familia (1, 54 y 55, relativos a la potestas del esclavo y del hijo, respectivamente). Para Robleda, en estos casos, que la potestad arranque del Derecho consuetudinario no implicó que ella no tuviera la sustancia o realidad de un verdadero derecho subjetivo. Dicha potestad se fundaría en la división de las personas, señalada en Gayo 1, 48-49. En el ámbito de los bienes, cita el pasaje de Gayo 2, 30, el que se refiere a la constitución del usufructo. En él, para Robleda, al hablarse de un retinere, efficere, habere, Gayo manifiesta la idea del ius como derecho y no como posición, pues: “...lo que viene retenido, creado (effectum), cedido, es aquello que se llama usufructo, nuda proprietas, ius, que uno tiene o del que uno dispone". Por último, entiende que, si bien es cierto Gayo no hablaba de ius in rem o ius in personam, si clasifica de este modo las acciones. Ahora bien, dado que la obligatio precede las acciones, precisamente esta trata de defender el ius, que para el acreedor implicaba la obligación ${ }^{92}$, cuya manifestación más evidente aparece en la definición de la acción personal, en Gayo 4, $2^{93}$.

Sobre la discusión, que excede las pretensiones de nuestro trabajo, pueden extraerse reflexiones importantes para determinar el concepto de la obligatio romana. En principio, si se considera que, en definitiva, en la época justinianea se encontraba ya desarrollada la idea de derecho subjetivo, uno debiese esperar que en las Instituciones de Justiniano hubiese un desarrollo distinto de la idea de las cosas incorporales y, en general, del ius, apareciendo ahora como una potestad o facultad, antes que como la cosa misma, que se examina desde el reflejo de la juridicidad. Una declaración en el sentido que apuntamos proporciona Justiniano en las sus Institutas, 1, 2, 12: "Omne autem ius, quo utimur, vel ad personas pertinet, vel ad res, vel ad actiones. Et prius de personis videamus. Nam parum est ius nosse, si personae, quarum causa constitutum est, ignorentur" " "Todo el derecho de que usamos, se refiere o a las personas, o a las cosas, o a las acciones. Tratemos primero de las personas. Porque es poco haber conocido el derecho, si se desconocen las personas por cuya causa se ha constituido").

Sin embargo, deteniéndonos en el esquema de las Institutas y en el tratamiento de las cosas incorporales y, particularmente de las obligaciones, necesariamente debe concluirse que, al menos la obligatio, como cosa incorporal, no fue considerada un derecho subjetivo, aun cuando hay una importante diferencia entre el pasaje de Gayo 2, 14 y el de Justiniano 2, 2, 3. Veamos.

\footnotetext{
92 En otro trabajo suyo, profundiza en esta idea, aun cuando él está dedicado básicamente al análisis del derecho real. En efecto, Robleda sostiene que, al incluir Gayo en 2, 14 dentro de las cosas incorporales la obligatio, es claro que debió haberse admitido la posición activa del acreedor, puesto que debió haber hecho falta una gran capacidad de abstracción para no ver en la posición del acreedor una potestad, véase RobLeDA (1977) pp. 40-41. Coincide Petit para quien los juristas romanos emplearon la palabra obligatio en un sentido muy amplio, para designar tanto el derecho de crédito, como el débito. Рeтiт (1989) p. 273.

93 Robleda (1972) pp. 9-13. Algunos autores, con una lectura procesal, hablan francamente de derechos subjetivos, a la hora de explicar la distinción clásica, propia del procedimiento formulario, entre actio in rem y actio in personam. Véase, por ejemplo, Fuenteseca (2001) p. 469: “...actiones in rem actiones in personam, en cuanto ambas actiones se convirtieron en instrumentos procesales, respectivamente, de los derechos reales (iura in re) y de los derechos de obligación (ius obligationes in personam)".
} 
Tanto Gayo, como Justiniano, definen y se refieren a las cosas incorporales de un modo similar. Según Justiniano, 2, 2, 3: "Incorporalis autem sunt, quae tangi non possunt, qualia sunt ea, quae in iure consistunt: sicut hereditas usufructus obligationes quoquo modo contractae" ${ }^{4}$. En tanto Gayo 2, 14 indica: "Incorporalis sunt, quae tangi non possunt, qualia sunt ea, quae <in> iure consistunt, sicut hereditas usufructus obligationes quoquo modo contractae" 95 .

La dificultad interpretativa se encuentra, pues, particularmente en la frase «quae <in> iure consistunt», puesto que hemos encontrado dos posibles traducciones al castellano. Antes, anotemos que entre el pasaje de Justiniano y el de Gayo, hay dos diferencias. En efecto, en el de Justiniano se expresa "Incorporales autem sunt», desapareciendo en la cita de Gayo, «autem» ${ }^{96}$. Más significativo, nos parece a nosotros, es la segunda diferencia, pues mientras en Justiniano 2, 2, 3, se afirma: "quae in iure consistunt», la partícula "in» no se encuentra en el texto original del palimpsesto veronés ${ }^{97}$. Veamos ahora en qué se traduce la dificultad interpretativa de que hemos hablado.

La frase "quae <in> iure consistunt», admitiría dos posibles traducciones al castellano. Con el empleo de la partícula «in» dentro de la frase, los traductores de las Institutas de Justiniano han entendido el pasaje como sigue: "Más son incorporales, las que no pueden ser tocadas; cuales son las que consisten en un derecho»" ${ }^{98}$. En efecto, en la traducción de las Instituciones de Justiniano de García del Corral, precisamente la frase se traduce de este modo ${ }^{99}$. En la que sin duda es la primera traducción al castellano de las Institutas de Gayo, de 1845, se presenta el texto de modo similar a la interpretación de García del Corral, a propósito de Justiniano. Dice la traducción: "Incorporales son las intangibles, como las que consisten en un derecho, a saber: la herencia, el usufructo o las obligaciones de cualquier modo que se hayan contraído» ${ }^{100}$. En cambio, en la traducción de Samper, advirtiendo la inexistencia en el texto original de la partícula «in», se ha permitido una traducción que juzgamos más adecuada al pensamiento jurídico romano. Así, la frase "quae <in> iure consistunt», puede significar: "pues su consistencia proviene del derecho»; en otros términos, que son realidades que existen solo jurídicamente, idealmente, si se quiere ${ }^{101}$.

Con independencia de la ausencia de la partícula «in» autorice una interpretación distinta a la traducción de Justiniano, consideramos, como se ha adelantado, que la traduc-

94 Para las Institutas de Justiniano, hemos seguido el texto de Krueger (1928).

95 Para el texto en latín de las Instituciones de Gayo, hemos seguido la publicación Huchke (1908) y también el de Samper (2000) p. 93.

96 Desde luego, es un agregado que no incide sustancialmente en la traducción, puesto que el adverbio autem puede traducirse -como se hace en García Corral-, como «más o además».

97 Así se deja constancia en la traducción de SAMPer (2000) p. VIII.

98 En el análisis dogmático, véase en esta línea, por ejemplo, Coronel Villalba (2007) p. 282.

99 Hemos empleado la traducción de García del Corral (1889) p. 38.

100 En efecto, nos referimos a la traducción al castellano de la obra que aparece en 1845. Véase, GAYo (1845): La Instituta de Gayo (Madrid, Imprenta de la Sociedad Literaria y Tipográfica) (en versión digital, puede consultarse en la biblioteca pixelegis, de la Universidad de Sevilla). También hemos encontrado esta traducción en Domingo (2002).

101 Véase SAmper (2000) p. 93. Samper ha tomado alguna licencia, sin alterar el sentido del texto, pues ha sustantivado el verbo "consistunt» para conjugarlo con el verbo provenir, que es precisamente uno de los sentidos del verbo «consistunt». 
ción de Samper es la más adecuada al pensamiento jurídico clásico. Y no solo decimos ello en razón de la evidente proximidad del texto de Gayo con el mundo clásico (que constituiría un argumento, de todos modos), sino que el tratamiento que le dispensa a la obligatio (seguida por cierto por Justiniano) nos hace pensar de este modo. En este sentido, parece notorio, en abono de la tesis de Villey, d'Ors y Gioffredi, que tanto en las Instituciones de Gayo, como en las Institutas de Justiniano, no se aborden los efectos de las obligaciones, como se conocen modernamente, sino la obligatio en $s^{102}$. En efecto, en ambas fuentes se abordan las causas por las que se contraen las obligaciones y sus modos de extinguir, para terminar con el estudio de los delitos (ya hemos estudiado por qué estos se encuentran al final). Y, en este contexto, como analizaremos en el apartado siguiente, el acreedor jamás contó con un genuino poder para compeler al deudor para la satisfacción de la prestación in natura; primero, como consecuencia de la idea de sujeción personal, después por el principio de la omnis pecuniaria que rigió el procedimiento formulario.

Con todo, una perspectiva complementaria puede ensayarse para abonar la argumentación que aquí viene indicándose, que nos viene dada de la regulación de la lex Aquilia, concretamente, del ignorado capítulo segundo. Como se sabe, el segundo capítulo (mencionado en Gayo 3, 215) ${ }^{103}$, se refiere al daño causado a un acreedor por el acreedor conjunto (adstipulor), al que se le sancionaba con la obligación de pagar la prestación al verdadero acreedor ${ }^{104}$. El Digesto solo dedica un pasaje bastante menor al segundo capítulo

102 Hagamos la salvedad de que si por efectos, comprendemos el pago de la deuda, entonces tales efectos se encuentran comentados. De lo que se trata acá, sin embargo, es de examinar las herramientas con las que cuenta el acreedor frente al incumplimiento.

103 El pasaje de Gayo reza: "Capite secundo <adversus> adstipulatorem qui pecuniam in fraudem stipulatoris acceptam fecerit, quanti ea res est, tanti actio constituitur" ("En el segundo capitulo se establece una acción contra el coestipulante que se hubiera dado por pagado en fraude del estipulante"). En el pasaje siguiente, es decir, 3, 216, se indica: "Quae et ipsa parte legis damni nomine actionem introduci manifestum est; sed id caueri non fuit necessarium, cum actio mandati ad eam rem sufficeret; nisi quod ea lege aduersus infitiantem in duplum agitur" ("Es evidente que en esa parte misma de la ley se ha introducido tal acción a título de daño; pero esto no era necesario disponerlo, ya que bastaba para ello la acción de mandato, aunque por esta ley se puede ejercitar una acción al doble contra el demandado que niega el hecho"). En relación con la fuente, Cannata (1992) p. 36, indica: "Quanto al secondo capo, la nostra sola fonte è Gai. 3, 215, poichè tanto il digesto (Ulp. D. 9, 2, 27, 4, con ogni probabilità interpolato per soppressione), quanto la instituzioni giustinianee (Inst. 4, 3, 12) si limitano ad informaci della sua desuetudine, senza indicarcene il contenuto. Gaio invece lo parafrasa, lasciando presumere un testo del tenore seguente: si adstipulor pecuniam in fraude stipulatoris acceptam fecerit, quanti ea res est, tantum aes stipulatori dare damnas esto". En efecto, antes del descubrimiento de las Instituciones de Gayo, el capítulo segundo fue desconocido, lo que dio lugar a toda suerte de especulaciones. Sobre esta cuestión y por todos, Gómez de la SERna (1863) p. 430.

104 La acceptilatio verbis cumplía la función de extinguir una deuda efectivamente pagada. Ahora bien, como indica Tomulescu (1970) pp. 193-195, tras la aparición de la figura de la solutio, es decir, el cumplimiento en las obligaciones de dar, la acceptilatio conservó solo la primera de las dos funciones, pero en el capítulo segundo reflejaba ambas. El fraude podía producirse tanto porque el adstipulator remitía la deuda sin consentimiento del acreedor principal, como si recibía efectivamente el pago. Coincide Cannata (1994) p. 152, en el sentido que el hecho sancionado era la remisión de la deuda que el adstipulor efectuaba a favor del deudor, en fraude del acreedor principal. Se trata, con todo, de una cuestión discutida. Así, por ejemplo, LÉvy-BrUHL (1958) pp. 507-517, sostiene que para configurar el fraude y el hecho sancionado en el capítulo segundo de la ley, era necesario que adstipulor recibiera efectivamente el pago, de manera que la obligación se extinguiera normalmente. Criticando esta posición, el ya citado Cannata (1994) p. 155 señala: “...nella generalità dei casi -e certo a questi soprattutto pensaba il legislatore, componendo il caput secundum-una remissione fraudolenta del debito, effettuata dal creditore solidale accesorio, non è affatto gratuita. Infatti, accanto alle ipotesi-che, questa si, con il Lévy-Brubl, 
en D. 9.2.27.4: "Huius legis secundum quidem capitulum in desuetudinem abiit" ("El segundo capitulo de esta ley cayó en desuso") y ello ocurrió porque, en el caso que se produjera dicho fraude, durante los tiempos clásicos la jurisprudencia otorgó la acción de mandato ${ }^{105}$.

Como señala Valditara, aun cuando se trata de una composición heterogénea, no sorprende la protección del crédito en el segundo capítulo, desde que los restantes capítulos de la ley se preocuparon de defender al propietario. Así, se entendería que se regulará la protección de la res incorporalis al lado de la salvaguarda de la res corporalis ${ }^{106}$. Por ello Grosso ha afirmado que el daño ilícito del crédito de otro venía concretamente considerado como una cosa que se destruía; quien estaba en condiciones de poderla destruir era el adstipulator, al perdonar el crédito al deudor, de manera semejante a la destrucción de cosas (corporales) de los otros dos capítulos. Más adelante agrega que este paralelismo puede derivarse de otro más antiguo, que distinguió entre la posición del obligado, en relación al crédito y la posición del siervo, en resguardo de su dueño. Así, la muerte del esclavo se equiparaba en cierto modo a la liberación del obligado (como consecuencia de la recepción del pago o de la remisión de la deuda) ${ }^{107}$.

El tratamiento que se otorgaba al crédito (en verdad, a la obligatio) en la lex Aquilia es bastante indicativo de que se buscaba sancionar el daño causado a una cosa y no la tutela de un derecho, tal como este se entendería modernamente. Nos parece convincente el argumento de Grosso, en orden a que había en la regulación aquiliana, una íntima conexión entre la obligatio primitiva y el dominium y por ello Grosso advierte que, aunque Gayo no pensaba en la lex Aquilia cuando clasificaba las cosas en corporales e incorporales (ni mientras explicaba esta, señaló de modo expreso que venía destruida una cosa incorporal), el lenguaje vivo de la sistemática de la lex Aquilia resulta, a este respecto, muy significativo ${ }^{108}$.

\section{LAS HERRAMIENTAS DE TUTELA: LA OBLIGATIO EN PERSPECTIVA PROCESAL}

Ya hemos advertido por qué, a nuestro juicio, carece de sentido referirse a la posición del acreedor como un verdadero derecho subjetivo de crédito $\mathrm{y}^{109}$, desde esta perspectiva, estamos en condiciones de abordar el alcance de la posición del acreedor. El análisis supone un doble recorrido; por un lado, reflexionar sobre la aplicabilidad (o no), de la dualidad débito-responsabilidad; de otro, las herramientas de tutela con las que contaba el acreedor.

possiamo considerare rarissime - in cui l'adstipulator sia mosso da simpatía, affetto, pietà verso il debitore o antipatía verso il creditore, vanno configurate quelle in cui egli operi in colussione con il debitore, ottenendo da questi un compenso, che potrà consistere in una somma, data o promessa, di denaro ovvero in prestazioni d'altro genere, abbiano queste o no valore economico".

105 En este sentido, por todos, D’Ors (1997) p. 435. Como explica Scherillo, la acción de mandato en favor del adstipulator se contemplaba expresamente en el pasaje gayano 3, 111. Sin embargo, como al tiempo de la de promulgación de la lex Aquilia no existía dicha acción, con posterioridad a esta se otorgó una acción propia, denominada actio depensi, en virtud de la ley Publilia, cuya nota característica era la litiscrescencia. SCHERILLO (1963) pp. 241-245.

106 Valditara (1994) pp. 833-834. En el mismo sentido, Natali (1970) p. 26.

107 Grosso (1964) pp. 791-795.

108 Grosso (1964) p. 795.

109 Betтi (1955) p. 176 y Betti (1969) p. 327, niega categóricamente que pueda hablarse de un derecho de crédito en favor del acreedor. 
Respecto del primer aspecto, es decir, la descripción de la obligatio romana como una dualidad débito-responsabilidad, habrá que responder negativamente. Si hemos concluido que no hubo derecho personal, es difícil pensar en la aplicación de una categoría que describe dogmáticamente la obligación moderna. Pelloso estima que, dado que la actio se resuelve en una situación jurídica sustancial, no puede ser considerada solo la herramienta procesal de protección de un derecho subjetivo preexistente, por diversas razones. Desde un punto de vista metodológico, indica, es un error atribuir a los juristas romanos un categoría dogmática moderna; desde el punto de vista hermenéutico, no existe nada en las fuentes que revele la posición del acreedor como un derecho; y, desde el punto de vista del histórico, no puede llevarse a alguna conclusión sobre la tutela del crédito, sin echar mano a la evolución de la obligatio ${ }^{110}$.

Como indica Betti, el deber primario de prestación se consume en la acción procesal, porque dicho deber es inexigible ${ }^{111}$. En otros términos, la exigencia de la condena, como dice Betti, la condemnari oportere, produjo la transición desde la obligación principal a la obligatio iudicati. El acreedor tenía solo una expectativa de condena que, verificada, producía la subrogación conducente a exigir aquello que se había determinado judicialmente; en otros términos, la condena producía un efecto sustantivo: el nacimiento de una obligación pecuniaria como consecuencia de la primera, que subrogaba la principal ${ }^{112}$. Pelloso ha entendido que la expresión vinculum iuris de la definición de Justiniano, no pudo significar sino un vínculo coercible mediante actio, es decir, que el vínculo jurídico se entendía únicamente desde la acción, de modo que la actio misma quedaba inmersa en la sustancia de la obligatio $^{113}$. Y, precisamente por ello, la litis contestatio aparece como modo de extinguir la obligación ${ }^{114}$.

Como señala Santoro, la actio no era el poder de un acreedor contra la persona del debitor, sino el poder para hacer efectiva la responsabilidad. Como no puede separarse el

110 Pelloso (2011) pp. 150; 153-154. Pelloso considera que la dualidad del proceso con el derecho materia fue obra de la primera mitad del siglo XX, considerándose la acción, entonces, como un verdadero derecho público subjetivo autónomo. Orestano (1959) pp. 792-794, explica que la unidad acción-ius, propia del Derecho romano, manifestada en la fórmula de Celso, D. 44, 7, 51, supuso considerar el proceso, como parte del Derecho privado y no como un Derecho público, organización diferenciada del ordo privatum.

111 Como indica Betтi (1969) p. 331, la obligación romana se caracterizaba porque fue siempre inexigible como tal, sin perjuicio de la coerción que recaía sobre el deudor de satisfacer la prestación para no verse sujeto a un procedimiento; en otros términos, que el acreedor, agrega el autor, no podía pretender la condena de la prestación misma.

112 Bетті (1955) pp. 11; 19-21; 31. La obligatio, para el autor, no supone técnicamente una prestación, sino la garantía del deudor de cumplir cierto hecho, sentido etimológico primario de la expresión praestare. Véase también, Betti (1969) pp. 322-323. Pelloso (2011) p. 232, indica: "Actio, dunque, anche in questa sede -seppir solo implicitamente- è ciò che, in buona sostanza, determina il passaggio da un vincolo a-giuridico a un vincolo guiridico e connota, come elemento discriminante, l'obligatio stessa. Tuttavia, asserire, sia alla luce dell'impostazione monosoggettiva, la quale, imperniata esclusivamente sulla angolazione del debitore, nulla dice circa la ttitolarità del creditore del diritto del diritto di esigere la prestazione, sia alla luce della interpretazione della necessitas quale elemento prezioso per riconoscere la correttezza e la congruità del dettati in relazione al diritto classico...".

113 Pelloso (2011) pp. 233; 235-236.

114 Como explica Gayo 3, 180-181. Para las diferencias entre la litis contestatio y la novatio, véase BetTI (1955) pp. 10-14. Para una explicación de la litis contestatio como modo extintivo de la obligatio, véase Pelloso (2011) pp. 234 y ss. 
poder del acreedor de la actio, Santoro entiende que no puede hablarse, en Roma, propiamente de un débito ${ }^{115}$.

Pero la afirmación del autor, en el sentido de descartar completamente el débito, no permite conciliar adecuadamente el pasaje gayano 4, $114^{116}$, que autorizaba al deudor satisfacer la deuda, aunque hubiese operado la litis contestatio. Es decir, parece inconciliable comprender que, a pesar de haber operado un modo de extinguir, aún así se admitiera la satisfacción del crédito primario. Betti entiende que dicha disfuncionalidad puede explicarse porque, en su concepto, la litis contestatio no producía la extinción íntegra de la obligación primaria, sino la extinción de la sola responsabilidad, subsistiendo el débito ${ }^{117}$. Por su parte, Santoro considera que la explicación puede admitirse para el Derecho romano, si se considera que la actio representaba la responsabilidad; en consecuencia, se extinguía la actio, pero no el debitum ${ }^{118}$. Pero el autor va más allá, al argumentar que la dicotomía demostrada en Gayo 4, 114, era un reflejo de la formación histórica de la obligatio. Esta, según Santoro, representó, hasta el período republicano, solo el ámbito de la responsabilidad, caracterizado por la sujeción personal. Por tanto, el desarrollo clásico de la obligatio habría importado la comprensión de esta como un vínculo que incorporaba el débito. Así, estima que en la época republicana «debere» significó la responsabilidad y nunca el deber de prestación. Y un argumento que nos ha parecido muy interesante, es el empleado por el autor a partir de la distinción que aparece en Gayo 3, 168; Gayo 3, 173, entre el pago o solutio y el pago formal (per aes et libram), para los casos de sentencia y confesión, que permite, a su vez, nuevamente advertir la diferenciación, muy clara, entre la responsabilidad, propia de

115 SANTORo (2009) p. 62.

116 Según Gayo 4, 114: "Superest ut dispisiamus, si ante rem iudicatam is, cum quo agitur, post acceptum iudicium satisfaciat actori, quid officio iudicis conueniat, utrum adsoluere an ideo potius damnare, quia iudici accipiendi tempore in ea causa fuerit, ut damnari debeat. Nostri praeceptores adsoluere eum debere existimant; nec interest, cuius generis sit iudicium. Et hoc est, quod uolgo dicitur Sabino et Cassio placere omnia iudicia absolutoria ese. $<$ Diuersae scholae auctoribus de stricti iuris iudiciis contra placuisse $>$ de bonae fidei iudiciis autem idem sentiunt, quia in eusmodi iudiciis autem idem sentiunt, quia in eusmodi iudicuus liberum est officium iudicis. Tantumdem et de in rem actionibus putant, quia formulae uerbis id ipsum exprimatur <ita demum reum condemnatum ese nisi arbitratu iudicis rem restituerit $>$........ (161/2 uersus)....... actum fuit”. Gayo expone la opinión de dos corrientes. Según Sabino y Casio, seguidos por Gayo, pagada la deuda después de la litis contestatio, el juez siempre debe absolver, frente a os juristas que opinaban que dicha absolución solo procedía en los juicios de buena fe y no en los de derecho estricto. Con todo, el pasaje, como se advierte, por ejemplo, de la traducción de Samper, adolece de varias lagunas. CANnATA (2001) p. 68., considera que del pasaje gayano se desprende el principio «omnia iudicia absolutoria esse», es decir, que el proceso romano está orientado primordialmente a la absolución del demandado, e, incluso, afirma, la condena pecuniaria del procedimiento formulario, está destinada a obtener la satisfacción de la prestación y no la condena directa. En otros términos, la condena, en efecto, no garantizaba el pago en casos como la insolvencia o en el supuesto de concurso de acreedores. De este modo, afirma: "Soltanto se il convenuto sia stato assolto, il proceso ha adempiuto la sua funzione di strumento per la restaurazione del ius, l'ordine giuridico compromesso del torto". (Disponible en < www.ledonline.it/rivistadirittoromano. (Fecha de la consulta: 1 de abril de 2013)>.

117 Betti (1955) p. 9.

118 SANTORO (2009) p. 67. Sostiene Santoro: "E l'actio che, attraverso la litis contestatio (che ha per effetto il rem in iudicium deducere) è 'indicium inclusa', 'in iudicium deducta' e perciò estinta -ove si tratti di actio in personam con fórmula in ius concepta dedotta in un iudicium legitimum -in applicazione della regula iuris 'bis de eadem re ne sit actio'. Perciò il fatto che Gaio parli qui piuttosto in termini di consunzione dell'obligatio è devoto alla stessa tendenza, già rifles a in 3.180, a trasporre il discorso sul piano sostanziale, per cui la litis contestatio è presa lì in considerazione tra i modi per i quali 'tollitur obligatio' nonostante la sopravvivenza del debito". 
la obligatio primitiva (que se extinguía mediante la solutio per aes et libram y el débito, que se integró en el concepto clásico y que admitió la solutio como forma de extinción. En el edicto del Pretor, la misma distinción entre un pago formal y la solutio, fue propia del desarrollo del vínculo obligatorio, como aparece en D. 42. 1. $7^{119}$.

La segunda cuestión, es decir, las herramientas de tutela del acreedor, no hacen sino extender el análisis propuesto. Veamos. El primer momento de la obligatio romana supone el cumplimiento por parte del deudor: en las obligaciones de dare, el cumplimiento se denomina solutio o pago, cuya satisfacción depende del tipo de prestación, certum o incertum. En las obligaciones de facere, el cumplimiento se denomina satisfactio, que siempre es incertum $^{120}$. Más complejo resulta determinar el contenido de la prestación de praestare, cuestión en la que no podemos detenernos en este trabajo ${ }^{121}$.

Cuando no se producía la satisfacción personal del deudor, el acreedor contaba entonces con algunas herramientas destinadas a obtener la satisfacción. Obviamente, las acciones del acreedor dependían del tipo de prestación a la que estaba sujeto el deudor. La pregunta entonces, se traducía en la siguiente: ¿qué podía demandar el acreedor, frente al incumplimiento contractual?

En el Derecho moderno se establece la idea de que el acreedor-demandante puede exigir el cumplimiento forzado, que supone la satisfacción de la misma prestación. Dejar "indemne" supone restituir aquello a lo que se estaba sujeto. Solo si no es posible, podría demandar una suma dineraria equivalente o, propiamente, la indemnización de perjuicios. $\mathrm{Ni}$ el Code, ni aquellos que se inspiran en él resuelven este aparente concurso de modo directo. En el Código civil chileno, tampoco e incluso, al contrario, como se desprende, para las obligaciones de hacer, en el artículo 1553 del Código Civil ${ }^{122}$. Pero el BGB admite la consagración del principio en los artículos 249, en relación con el artículo 251 del Código Civil.

\footnotetext{
119 SANTORo (2009) pp. 67-71; 78-79; 111.

120 Sobre esta materia, véase, por todos, SARgento (1981) pp. 532-540.

121 Para esta materia, remitimos al extenso trabajo de Cannata (1969) pp. 11-13.

122 La doctrina más tradicional chilena, sin embargo, entiende que el acreedor debe seguir cierto orden de prelación a la hora de exigir la prestación, porque el crédito ofrece un derecho principal para exigir el cumplimiento forzado y solo el derecho de reclamar perjuicios compensatorios cuando el cumplimiento no es posible. Entre los argumentos, podemos indicar los siguientes: a) el artículo 1672, ubicado en la regulación de la pérdida de la cosa debida, demuestra que el Código Civil solo admitiría la demanda de perjuicios compensatorios frente a la imposibilidad del cumplimiento forzado; b) el artículo 1537, a propósito de la cláusula penal, permitiría una regla excepcional en cuanto a la posibilidad del acreedor de escoger entre el cumplimiento forzado y la pena, de modo que, por el contrario, la regla general no admitiría la elección; c) tanto el principio de la fuerza obligatoria de los contratos (artículo 1545), como el de la identidad del pago (artículo 1569), se verían vulnerados, si se otorgara la posibilidad de entregar una cosa distinta de la pactada; d) vinculado con lo anterior, se estima que, por esta vía, las obligaciones de dar se transformarían en obligaciones alternativas; e) finalmente, se estima que la condición resolutoria tácita, envuelta en todo contrato bilateral, impediría, tratándose de obligaciones de dar, demandar indemnización de perjuicios derechamente, en la medida de que, dicha acción debe deducirse con la resolución o de cumplimiento forzado. Precisamente, los artículos 1553 y 1555, que se refieren a las acciones tratándose de obligaciones de hacer y no hacer, respectivamente, confirmarían que el Código civil optó por una regla diversa en el caso de obligaciones de dar. Véase, Abeliuk (2001) pp. 812-813; Gatica Pacheco (1959) pp. 27-28; y, Fueyo (2004) pp. 347-348. La dogmática más moderna chilena, ha venido opinando en sentido completamente contrario. Entre otros, véanse Pizarro Wilson (2008) pp. 400 y ss.; Vidal Olivares (2007) pp. 517 y ss.
} 
En el Derecho romano, debe diferenciarse la época de evolución de la obligatio, correspondiendo la aplicación de uno u otro procedimiento. En el contexto de las acciones de la ley ${ }^{123}$, el ejercicio de dichas acciones estuvo representado por las acciones personales $\mathrm{y}^{124}$, conseguida la sentencia, por la manus iniectio ${ }^{125}$, que se articuló como uno de los mecanismos destinados a reemplazar la venganza privada y a consagrar la heterotutela, en el contexto de un procedimiento, frente a un magistrado ${ }^{126}$. Como advierte Purpura, la manus iniectio no se consagró solo como un mecanismo de venganza, sino que se trató de un genuino procedimiento de ejecución, en el sentido de que el deudor debía trabajar en favor del acreedor, para sarisfacer el crédito, equiparándose la situación del deudor a la del nexi ${ }^{127}$.

El último paso estaría representado por la espiritualización del vínculo. Se estima que con la lex Poetelia Papiria, del 326 a.c. ${ }^{128}$, se abolió de modo definitivo la prisión por deudas ${ }^{129}$. Ello habría permitido el paso de un vínculo centrado en la acción física, a la vin-

123 Según Arangio-Ruiz (1945) p. 11, el término actio, en Derecho romano, designaba el acto jurídico mediante el cual una persona afirmaba solemnemente su derecho, a fin de que fuera reconocido (si fue este desconocido) o bien habiendo sido reconocido fuera perturbado en su goce (de ahí que fuese realizable).

124 Como se sabe, el procedimiento de acciones de la ley contempló acciones declarativas y ejecutivas. Entre las acciones declarativas, destacan, en lo que respecta a nuestro interés, la actio sacramentum in personam, de aplicación general, aunque apenas quedan vestigios, por lo que no se sabe con certeza cuál era el procedimiento, ni el alcance de la acción, aun cuando se estima que debió haber sido similar a la actio sacramentum in rem (Gayo IV, 13 a 17); la legis actio per iudicis arbitrive postulationem, cuya aplicación se limitaba a los casos señalados en la ley. Las XII Tablas la estableció para hacer efectiva la promesa derivada de la stipulatio. También se empleó para la división de la herencia, conforme a las XII Tablas y en virtud de la lex Licinia, del 210 a.c., se admitió para la división de una cosa común (Gayo IV, 17a); finalmente, la legis actio per condictionem. Es la menos antigua, pues fue introducida por la lex Silia, del siglo III a.C. para recamar deudas pecuniarias ciertas. Para reclamar cualquier cosa incierta, fue introducida por la lex Calpurnia, de mediados del siglo II a.c. Las razones de su dictación no son muy claras, pues se superpuso a la per sacramentum in personam y a la legis actio per iudicis arbitrive postulationem (el propio Gayo IV, 19-20 se plantea la interrogante).

125 La manus iniectio fue el procedimiento diseñado en las XII Tablas para ejecutar una sentencia dictada o en el caso de la confesión. Solo podía ejecutarse pasados 30 días, contados desde la dictación del fallo (Gayo 4, 21). Además, se extendió a otros ámbitos, en los que se fingía la existencia de la sentencia: a) la lex Publilia de sponsu, confirió la acción a favor del fiador (sponsor) que pagaba la deuda al acreedor, en contra del deudor principal, si este no pagaba dentro de los 6 meses; b) la lex Furia de sponsu, a favor del cofiador que pagaba al acreedor más de lo que proporcionalmente le correspondía (Gayo, 4, 22). Por último, Gayo, 4, 23, indica casos en los que se otorgó la denominada manus iniectio pura, es decir, directamente, sin necesidad de sentencia judicial, ni fingir la existencia de esta. Gayo menciona dos: la lex Furia testamentaria, a favor del heredero y contra el legatario que obtuvo más de mil ases; y, la lex Marcia de feneratoribus (104 a. C.), contra el prestamista que cobraba un interés usurero. Aunque no lo menciona Gayo, se sabe que la manus iniectio se aplicó también a la lex Aquilia. Sobre la manus iniectio, véase Talamanca (1987) pp. 9-12.

126 Zimmermann (1996) p. 3. Véase también, Dumont (1963) p. 13.

127 Véase Purpura (2007) p. 4.

128 La lex habría sido redactada por los cónsules Poetelio Libo Visolo y Lucio Papirio Cursor, cónsules el año 326; otros, sin embargo, indican que la lex habría sido preparada por Poetelio, dictador en el 313 a.C. Véase CARLSEN (1997) pp. 407-408.

129 El texto de la Ley, así como las circunstancias de su aparición, se encuentran narrados por Tito Livio, $A b$ Urbe Condita, 1. VIII, cap. 28. Rodríguez Ennes (2009) p. 95, relata: "Un joven de óptima familia, debido a la situación económica desastrosa de su padre, fue constreñido a caer en manos de un usurero; este, vicioso y privado de escrúpulos, intentó estuprar al deudor nexus (es decir, al hijo), ut florem aetatis fructum adventicium crediti ratus; y frente a su desdén y a sus resistencia optó por desnudarlo y golpearlo ferozmente, La víctima, con el torso ensangrentado se precipitó entre los viandantes, mostrando sus heridas y denunciando su cruel y libidinoso acreedor. Por todo ello, suscitó la indignación de los presentes ante la injuria sufrida por un ciudadano de tierna edad, y la multitud lo 
culación patrimonial del deudor ${ }^{130}$. Pero lo cierto es que dicha afirmación debe matizarse. En primer lugar, dicha lex, cualquiera fuera su contenido, abolió el nexum exclusivamente; en segundo lugar, el alcance de la lex es discutido, pues esta, en definitiva, solo vino a dar solución a la situación de los nexi que se encontraban en estado de prisión con anterioridad a la lex, lo que quiere decir que no abolió de modo absoluto (ni para el futuro), la sujeción personal del deudor ${ }^{131}$.

Abolido el procedimiento de acciones de la ley por las leyes Ebucia y Juliaa ${ }^{132}$, el procedimiento formulario dio paso a un procedimiento ejecutivo de carácter patrimonial. Aun así, hay que tener presente que, siguiendo a Voci ${ }^{133}$, la manus iniectio y, en consecuencia, la sujeción personal, quedó vigente aun después de la dictación de la lex Poetelia Papiria, pero no con la forma de la manus iniectio per manus iniectionem, por cuanto quedaba excluida ahora la muerte o la venta del deudor; la manus iniectio se traduciría en el trabajo que el deudor debía realizar en favor del acreedor, para satisfacer el crédito, debiendo este último proporcionarle la alimentación y el descanso.

Con todo, el procedimiento ejecutivo de carácter patrimonial antes descrito supuso el ejercicio de la acción personal. Como indica Fuenteseca, en época clásica, la división fundamental de las acciones se había limitado a las figuras de la actio in rem y de la actio in personam. Agrega: "Ambas formulaciones proceden históricamente de las legis actiones y se insertaron en las formulae del procedimiento formulario. Nos hallamos ante un testimonio claro de la doble linea evolutiva de la historia del proceso romano: una que conduce desde la legis actio sacramento in rem (=vindicationes) hasta la actio in rem del proceso formulario, y otra que

acompañó tumultuosamente a la curia, llamando a los cónsules, a los que tras mostrarles las laceraciones, impetraron su intervención a fin de reparar adecuadamente el honorable abuso".

130 En este punto, la doctrina romanista no tiene dudas. Véase, por todos, Fuenteseca (2011) p. 495 y BisCardi (1994) pp. 20-21. Como afirma Peppe (2009) pp. 131-132, toda la temática de la lex Poetelia, al menos a la luz de lo narrado por Livio, se refería a la clase plebeya, que en definitiva era la menos favorecida en la evolución que en esos momentos tenía la sociedad romana. Y agrega un dato interesante: La lex emplea la expresión, según refiere Livio, obnoxium, como opuesta a la libertad, que Peppe identifica con obligatus.

131 Sobre esta cuestión, véase Voci (1966) pp. 423-424. Según Voci: "Il regime fin qui esposto fu modificato dalla lex Poetelia, del 326 a.c. Che questa legge abbia abolito l'esecuzione personale, è da escludere: certo la attenuò. L'esecuzione personale existe ancora in età classica: fonti litterarie e giuridiche la ricordano; e l'editto del pretore contiene norme che la regolano". Purpura (2009) p. 58, se pronuncia en un sentido similar: "Tuttavia, una significativa certezza, che in passato ha sorretto in dottrina l'ipotesi che il diritto classico rinnegasse del tutto la barbarica usanza, sembra oggi venuta a mancare: è stato infatti erroneamente scritto che bisogna tenere presente che la responsabilità corporale del debitore vivente era caduta gì̀ con la lex Poetelia e que-sti non rispondeva ormai più col proprio corpo da vivo, non si vede perchè dovesse rispondere col corpo da morto. Ci sembra invece certo che la Lex Poetelia Papiria del 339-313 a.C., abolendo il nexum, non sostitui affatto l'esecuzione personale con la patrimoniale. Non solo l'esecuzione personale per debiti si perpetuò a lungo e certamente non scomparve nel iv sec. a. C., ma soltanto alla fine del iv sec. d.C. cominciarono ad essere proibite le carceri private, mirando alla sostituzione con le pubbliche e, come è noto, attraverso l'arresto personale per debiti e afflizioni di ogni sorta in età medievale, essa è rimasta teoricamente in vigore in Italia almeno fino al Codice Civile del 1942!”. Esta también es la opinión de Magdelain, en este punto Tito Livio y Sallustio, quien a propósito del asunto de Catilina, hace una mención a la lex, son perfectamente coincidentes en que dicha ley no modificó hacia el futuro la ejecución sobre la persona, sino que creó un mecanismo de persecución patrimonial precursor de la cessio bonorum. MAGDELAIN (1987) pp. 815-816.

132 Si bien es cierto las acciones de la ley fueron sustituidas por las acciones formularias, lo que no está claro y es sumamente discutido por la doctrina es la forma en la que se produjeron dichas aboliciones y a cuáles leyes, exactamente, se refiere Gayo en su pasaje. Sobre el tema, véase Levy-Bruhl (1960) pp. 324 y ss.

133 Voci (1966) p. 424. En un sentido similar, Santoro (2009) p. 111 y Purpura (2009) p. 59. 
parte desde las dos legis actiones per iudicis postulationem y per condictionem y conduce hasta la actio in personam clásica, en cuya fórmula se exige un débito pecuniario..."134.

En el procedimiento formulario, tratándose de la acción personal, como hemos visto, rigió el principio de la omnis condemnatio pecuniaria ${ }^{135}$. Como explica Fuenteseca, la afirmación de Gayo dejó planteado el enigma de una condemnatio ipsa rem de época antigua. Pero Fuenteseca avanza la idea de que Gayo pudo haber operado con una evidente confusión a la hora de explicar instituciones antiguas con una lectura de su propia época. En efecto, la condemnatio ipsa rem no sería otra cosa que la vindicación derivada de la sacramentum in rem, que permitía, mediante vindicaciones, hacer valer un poder dominical sobre personas o cosas. Gayo, en cambio, habría operado sobre la idea de la clara distinción entre acciones reales y personales ${ }^{136}$.

La reclamación de daños no supuso, entonces, una serie de remedios disponibles para el acreedor derivados del incumplimiento y, en particular, el concepto de "daño" (léase responsabilidad contractual) como un específico tipo de remedio fue ajeno al Derecho romano. En las acciones de derecho estricto, que contenían una intentio certa, el juez condenaba al valor equivalente a la prestación que no se había ejecutado, es decir, se seguía el principio de la aestimatio rei. Se trataba, en consecuencia, de una norma enteramente objetiva, careciendo de real importancia las pérdidas sufridas al margen del valor de la cosa. La situación fue diferente en el caso de las acciones con intentio incerta. Aquí, las circunstancias propias de la víctima fueron introducidas por el juez para estimar qué suma de dinero era equitativo proporcionar al demandante. Es evidente que este criterio no coincide, necesariamente, con el valor del objeto de la prestación. Justiniano, 4, 6, 30 dice al respecto: "In bona fidei autem indiciis libera potestas permitti videtur iudici ex bono et aequo aestimandi, quantum actori restitui debeat"137. Ello, sin perjuicio de que el iudex podía condenar al deudor a una cantidad determinada de dinero, según sus posibilidades económicas, in quod facere potest, en determinados casos ${ }^{138}$.

134 Fuenteseca (2011) pp. 467-468. En efecto, Gayo dedica el cuarto comentario a las acciones y comienza indicando que estas se dividen en dos: la actio in rem y la actio in personam. Aun así, como indica el mismo Fuenteseca (2011) pp. 469-470, no debe perderse de vista que la clara distinción gayana se produce en momentos en que el sistema contractual romano se cerraba. Por eso, destaca, no resulta del todo claro el paso de evolución de las acciones de la ley que pueden caracterizarse de personales (sacramentum in personam, iudicis postulatio y condictio). Y la duda se presenta porque el mismo Gayo 4, 20, indica que se desconoce la razón por la que se introduce una acción personal de carácter general, cuando: "potuerimus aut sacramentum aut per iudicis postulationem agere, ualde quaeritur".

135 La referencia proviene de Gayo 4, 48: "Omnem autem formularum, quae condemnationem habent, ad pecuniariam aestimationem condemnatio concepta est. Itaque et si corpus aliquod petamus, uelut fundum hominem uestem argentum, iudex non ipsam rem condemnat eum, cum quo actum est, sicut olim fieri solebat, <sed >aestimata re pecuniam eum condemnat" ("La condenación de todas las fórmulas que la lleven consiste en una cantidad de dinero. Si pedimos una cosa corporal, por ejemplo, un fundo, un esclavo, un vestido, oro o plata, el juez no condena al demandado a la cosa misma, como solía hacerse antes, sino que le condena a la cantidad de dinero en que se ha valorado el objeto de la cosa").

136 Fuenteseca (2011) pp. 477-480; 483

137 Para un estudio de la litis aestimatio, véase, Fuenteseca Degeneffe (2006) pp. 403-412. El concepto se refería tanto a valoracion que el juez debía hacer de la prestación insatisfecha, como al cumplimiento de la suma pecuniaria fijada por el juez; concretamente, el carácter o no de modo de adquirir que tendría la litis aestimatio. 138 Véase Prado Rodríguez (2010) especialmente, pp. 363 y ss. También en Prado Rodríguez (2012) pp. 103-126. 
Precisamente, es a propósito de las acciones incerta que el concepto de daño, como se le conoce técnicamente, entra en escena, vinculado ahora al principio del id quod interest, opuesto al limitado concepto del quanti ea res est (que limita el daño al valor de la cosa), que se caracteriza por un criterio más subjetivo y equitativo ${ }^{139}$.

En cuanto al procedimiento formulario, de la cosa juzgada emanaba la consecuencia de que el demandante, si obtenía sentencia favorable, podía pedir la ejecución, aún con oposición del demandado. El plazo era de treinta días, contados desde la sentencia. La acción se denominaba actio iudicati: la concedía el pretor contra el condenando y contra el confessus y siempre era personal. La ejecución tenía, ahora, carácter patrimonial. La actio iudicati vino a reemplazar, así, a la manus iniectio. El pretor podía decretar la missio in bona, que autorizaba al demandante para tomar posesión de los bienes del demandado, aunque el acreedor no tuviese carácter de dueño o poseedor, haciéndolo como mero detentador ${ }^{140}$.

El acreedor debía publicar, por espacio de 30 días o 15 si había fallecido (la denominada proscriptio), la solicitud de ejecución de la sentencia. Si en ese plazo no cumplía el deudor, había dos alternativas: la cessio bonorum (posible en virtud de la lex Iulia de bonis cedendis, 17 a.C. $)^{141}$; o la subasta pública al mejor postor (bonorum emptor) ${ }^{142}$. La posibilidad de la venta de los bienes del deudor representó un paso adelante, sin duda alguna, en relación con la ejecución, pero el carácter personal de la obligatio no desapareció. Dicho carácter personal ha sido puesto de manifiesto por Purpura, quien indica que el deudor privado de sus bienes era equiparado, como se demuestra de varios pasajes de Gayo (entre ellos Gayo 2, 98; 3, 77; 80 y 81), a un muerto. Pero además Purpura agrega que la bonorum venditio recaía sobre todos los bienes del deudor, con independencia de la satisfacción o valoración del crédito, precisamente a la luz del principio de la condena pecuniaria del procedimiento formulario ${ }^{143}$. Y, siguiendo a Prado, la bonorum venditio habría importado, además de la venta de todos los bienes del deudor, la nota de infamia, es decir, la pérdida de la dignidad social, como consecuencia del crédito insatisfecho ${ }^{144}$.

Ahora bien, estas acciones de carácter patrimonial, prueban a nuestro juicio que el crédito, estrictamente, no constituye un derecho personal. Como se ha propuesto, el ius no es un poder, como se comprende en el Derecho moderno, ni la obligatio un deber de pres-

139 Sin embargo, fue un principio desarrollado caso a caso y, por lo mismo, no existe una sistematización de lo que por el principio debe entenderse. No obstante, en la jurisprudencia se perfilaron las bases de los que en medioevo se sistematizaría como daño emergente y lucro cesante, como por ejemplo, en este pasaje de Ulp. D. 19, 1, 1, pr.: "Si res vendita non tradatur, in id quod interest agitur, hoc est quod rem habere interest emptoris: hoc autem interdum pretium egreditur, si pluris interest, quam rest valet vel empta est".

140 Como indica Voci (1966) p. 425, el missi, tenía la calidad de custodio de todos los bienes del deudor; correlativamente, el deudor pierde la capacidad de disponer de sus propios bienes.

141 Hay múltiples aspectos que se discuten sobre el origen y contenido y condiciones de aplicación de la cessio bonorum. En principio, no se sabe si fue dictada en la época de César, Augusto o bien se trató de la introducción operada por los pretores previamente. Por otra parte, algunos consideran que el instituto solo permitía liberarse al deudor en los supuestos de insolvencia. Para estos problemas y la bibliografía que contiene, remitimos al trabajo de Schiavo (2009) pp. 125-133. Véase también Soza Ried (2007) pp. 621 y ss.

142 Para la explicación general del procedimiento de ejecución, véase García Garrido (2005) pp. 80-82; VocI (1966) pp. 424-427.

143 Purpura (2006) pp. 4-5; 9.

144 Véase Prado (2010) p. 366. 
tación para con el acreedor, en términos que este pudiese exigir la satisfacción del crédito mismo. La mejor prueba de ello es que no se advierte un tránsito marcado del vínculo personal al patrimonial. En el procedimiento de ejecución propio del procedimiento formulario, permanece latente el carácter personal del vínculo: la posibilidad de la venta del íntegro patrimonio del deudor y la nota de infamia son solo ejemplos. Por eso, puede concluirse que la definición de Justiniano, cuando expresa que la obligatio es un iuris vinculum, no se refiere tanto a la patrimonialización de la relación obligatoria, como se suele acentuar, sino que destaca que dicha relación es ideal, en el sentido que su existencia puramente jurídica $y$, en este sentido, no puede contraponerse absolutamente el carácter patrimonial con los rasgos personales del vínculo que permanecieron, todavía con el procedimiento formulario.

\section{BIBLIOGRAFÍA}

Abeliuk Manasevic, René (2001): Las Obligaciones, tomo I. (Santiago, Temis-Editorial Jurídica de Chile, cuarta edición actualizada y aumentada).

Aedo Barrena, Cristián (2009a): "La actio aquiliae: concepto, características y desarrollo decretal posterior. Lecturas desde el capítulo tercero", Revista de Derecho, 16 Nº1.

Aedo Barrena, Cristián (2009b): "Los requisitos de la lex Aquilia, con especial referencia al daño. Lecturas desde las distintas teorías del capítulo tercero", Ius et Praxis, $15 \mathrm{~N}^{\circ} 1$.

Amunátegui Perelló, Carlos (2009): Origen de los poderes del pater familias. El pater familias y la patria potestas (Madrid, Dykinson).

Arangio-Ruiz, V. (1945): Las acciones en el derecho privado romano (trad. de Faustino Gutiérrez Alviz, Madrid, Editorial Revista de Derecho Privado).

Arangio-Ruiz, V. (1986): Instituciones de Derecho romano (trad. de la décima edición italiana por José Caramés Ferro, Buenos Aires, Depalma, reimpresión primera edición).

Arias Bonet, Juan Antonio (1988): "Sobre la permanencia de la actio legis Aquiliae en la doctrina jurídica medieval”, en: AA.VV. Homenaje a Juan Berchmans Vallet de Goytisolo, vol. IV (Madrid, Junta de Decanos de los Colegios Notariales de España, Consejo General del Notariado).

Arias Ramos, J. y Arias Bonet, J.A. (1991): Derecho romano, tomo II: Obligaciones, familia, sucesiones (Madrid, Editorial Revista de Derecho Privado, decimoctava edición).

Betti, Emilio (1955): La Struttura dell'obbligazione romana e il problema de la sua genesi (Milano, Giuffrè).

Betti, Emilio (1962): Istituzioni di Diritto Romano, vol. I, II (Padova, Cedam).

Betti, Emilio (1969): Teoría General de las Obligaciones (trad. de José Luis de Los Mozos, Madrid, Editorial Revista de Derecho Privado).

Biondi, Biondo (1962): "Sponsio e stipulatio. Divagazioni intorno alla storia del contratto, dell'obligatio, delle garanzie personali”, $B I D R \mathrm{~N}^{\circ} 65$.

Biscardi, A. (1994): "La genesi del concetto classico di obligatio", en: Francisco Javier Paricio (coord.), Derecho romano de obligaciones: homenaje al profesor José Luis Murga Gener (Madrid, Centro de Estudios Ramón Areces).

Blánquez Fraile, Agustín (1961): Diccionario Latino Español (Barcelona, Sopena). 
Bonfante, Pedro (1959): Instituciones de Derecho Romano (trad. de la octava edición italiana por Luis Bacci y Andres Larrosa, revisada por Fernando Campuzano Horma, Madrid, Reus, segunda edición).

Bonfante, Pietro (1979): Corso di Diritto Romano, tomo IV (Milano, Giuffrè).

Castresana, Amelia (2001): Nuevas lecturas de la responsabilidad aquiliana (Salamanca, Ediciones Universidad de Salamanca).

Cannata, Carlo Augusto (1969): Per lo studio della responsabilità per colpa nel Diritto romano classico (Milano, La Giolardica).

Cannata, Carlo Augusto (1992): "Delitto e obbligazione", en: AA.VV. Illecito e pena privata in età republicana (Napoli, Edizioni Scientifiche Italiane).

Cannata, Carlo Augusto (1994): "Considerazioni sul testo e la portata originaria del secondo capo della "lex Aquilia", Index $\mathrm{N}^{\circ} 22$.

Cannata, Carlo Augusto (1996): Sul problema della responsabilità nel Diritto Privato Romano (Catania, Librería Editriche Torre Catania).

Cannata, Carlo Augusto (2001): "Omnia iudicia absolutoria esse", en: Atti del Convegno processo civile e proceso penale nell'esperienza giuridica del mondo antico. In memoria de Arnaldo Biscardi, Rivista di Diritto Romano.

Cannata, Carlo Augusto (2003): Corso di Istituzioni di Diritto Romano (Turín, Giappichelli).

Carlsen, Jesper (1997): "Lex Poetelia Papiria", en: The Historical Encyclopedia of World Slavevery, vol. I (Santa Bárbara, ABC).

Cesarini Sforza, Widar (1968): "Diritto soggetivo", en: Enciclopedia del Diritto, tomo XII (Milano, Giuffrè).

Coronel Villalba, Gustavo (2007): "Los iura in re y las res: tradición romanística en el Código civil argentino", en: Carvajal, Patricio (editor), Estudios de Derecho romano en homenaje al Prof. Dr. D. Francisco Samper (Santiago, Librotecnia).

De los Mozos Touya (1994): "Clasificación de las fuentes de las obligaciones en las Instituciones de Gayo y de Justiniano y su valor sistemático en el moderno Derecho civil”, en: AA.VV., Seminarios Complutenses de Derecho romano, tomo VI (Madrid, Fundación Seminario de Derecho Romano «Urcisino Alvarez»).

De Miguel, Ramiundo (1861): Diccionario Latino-Español Etimológico (s.l.).

De Valbuena, Manuel (1860): Diccionario Español-Latino, (París, Librería de Garnier Hermanos).

De Visscher, Fernard (1928): "Les origines de l'obligation «ex delicto»", Reveu Historique de Droit Français et Étranger, cuarta serie, 7 año.

Domingo, Rafel (coord.) (2002): Textos de Derecho romano (Madrid, Aranzadi).

D’Ors, Álvaro (1953): “Aspectos objetivos y subjetivos del concepto de ius”, en: AA.VV. Studi in memoria di Emilio Albertario (Milano, Giuffrè).

D’Ors, Álvaro (1954): "Ius en sentido objetivo-subjetivo", AHDE, XXIV.

D’Ors, Álvaro (1997): Derecho Privado Romano (Pamplona, Ediciones Universidad de Navarra, novena edición).

Dumont, François (1963): “Obligatio", en: AA.VV. Mélanges Philippe Meylan, vol I: Droit Romain (Paris, Imprimiere Centrale de Lausanne). 
Feenstra, Robert (1979): "L'actio legis Aquiliae utilis en cas d'homicide chez les glossateurs", en: AA.VV. Maior viginti quinque anis. Essays in commemoration of the Sixth lustrum of the Institute for Legal History of the University of Utrecht (Assen, Spruit).

Fernández de Buján, Federico (2004): Sistema contractual romano (Madrid, Dykinson, segunda edición).

Ferrini, Contardo (1930): La legitimazione attiva nell' "actio legis Aquiliae, en: El Mismo, Opere di Contardo Ferrini, vol. V (Milano, Ulrico Hoepli).

Fuenteseca Degeneffe, Margarita (1997): El delito civil en Roma y en el Derecho español (Valencia, Tirant Lo Blanch).

Fuenteseca Degeneffe, Margarita (2006): "La litis aestimatio desde la perspectiva del procedimiento formulario romano", $A F D U D C \mathrm{~N}^{\circ} 10$.

Fuenteseca Degeneffe, Margarita (2008): "Dare facere oportere y los orígenes de la obligatio ex contractu", RIDA $\mathrm{N}^{\circ} 55$.

Fuenteseca, Pablo (2001): "La obligatio como vinculum iuris (civilis) y la obligatio rei pignoris causa", en: AA.VV., Iuris Vincula. Studi in onore di Mario Talamanca, tomo III (Nápoles, Jovene Editore).

Fueyo Laneri, Fernando (2001): Cumplimiento e incumplimiento de las obligaciones (Santiago, Editorial Jurídica de Chile, tercera edición actualizada).

García del Corral, D. Idelfonso (1889): Cuerpo de Derecho Civil Romano, Primera Parte: Instituta-Digesto (Barcelona, Jaime Molinas Editor).

García Garrido, Manuel Jesús (2005): Derecho privado romano (Madrid, Ediciones Académicas, decimocuarta edición).

García Garrido, Manuel (2005): Casuismo y jurisprudencia romana (Responsa) (Madrid, Ediciones Académicas, segunda edición).

Gatica Pacheco, Sergio (1959): Aspectos de la indemnización de perjuicios por incumplimiento de contrato (Santiago, Editorial Jurídica de Chile).

Gaudement, Jean (2001): "Naissance de la notion d'obligation dans le droit de la Rome Antique", en AA.VV. Iuris Vincula. Studi in onore di Mario Talamanca, tomo IV (Napoli, Jovene Editore).

Gioffredi, Carlo (1967): "Osservazioni sul problema del diritto soggettivo nel Diritto romano", en $B I D R \mathrm{~N}^{\circ} 70$.

Gómez de la Serna, Pedro (1863): Curso histórico exegético del Derecho romano comparado con el español, tomo II (Madrid, Librería Sánchez, tercera edición).

Grosso, Giuseppe (1961): “Contratto (storia)”, en: Enciclopedia del Diritto, tomo IX (Milano, Giuffrè).

Grosso, Giuseppe (1964): "La distinzione fra "res corporales" e "res incorporales" e il secondo capo della "lex Aquilia”, en: Antonio Guarino (a cura di), Synteleia Vicenzio Arangio Ruiz (Napoli, Editore Jovene Napoli).

Grosso, Giuseppe (2001): "Nexum (e nexus)", en El mismo, Scritti storico giuridici, tomo III: Diritto Privato, persone, obbligazioni, succesioni (Torino, Giappichelli).

Guarino, Antonio (1997): Diritto Privato Romano (Napoli, Editore Jovene Napoli, decimo primera edición). 
Guarino, Antonio (2011): “Obligatio est iuris vinculum”, en: AA.VV., Iuris Vincula. Studi in onore di Mario Talamanca, tomo IV (Napoli, Jovene Editore).

Guzmán Brito, Alejandro (2001): Derecho Privado Romano, tomo I (Santiago, Editorial Jurídica de Chile).

Glare, P.G.W. (1983): Oxford Latin Dictionary (London, Oxford Clarendon Press).

Guzmán Brito, Alejandro (2003): "Historia de la denominación del derecho-facultad como subjetivo", Revista de Estudios Histórico-Jurídicos $\mathrm{N}^{\circ} 25$.

Hernández Tejeiro, F. (1946): "Sobre el concepto de potestas", $A H D E \mathrm{~N}^{\circ} 17$.

Huschke (1846): Ueber das Recht des Nexum uns das alte röm, Schuldrecht, Leipzig, 1846 (Disponible en <http://reader.digitale-sammlungen.de/de/fs1/object/display/ bsb10565630_00015.html>.

Huchke, Eduardo (1908): Gai Institutionum. Commentarii Quattuor (Lipsiae, segunda edición).

Jörs, Paul y Kunkel, Wolfang (1965): Derecho Romano Privado (trad. de la segunda edición alemana por L. Prieto Castro, Barcelona, Editorial Labor, reimpresión de la primera edición).

Kelly, John (1964): “The meaning of the lex Aquilia”, $L Q R \mathrm{~N}^{\circ} 80$.

Körting, Gustav (1907): Lateinisch-Romaniches Wörterbuch (Etymologishes Wörterbuch der Romanischen Hauptsprachen), (Paderborn).

Krueger, Paul (1928): Institutiones (Berolini, decimoquinta edición).

Lantella, Lelio (1971): "Note semantiche sulle definizioni di «obligatio», en: AA.VV. Studi in onore di Giuseppe Grosso, vol. IV (Torino, Giappichelli).

Lazo, Patricio (2004): "El método de comparación de casos: examen de resultados", Revista de Estudios Histórico Jurídicos $\mathrm{N}^{\circ} 26$.

LÉvy-Bruhl, H. (1958): "Le deuxième chapitre de la loi Aquilia”, RIDA Nº 5.

Levy-Bruhl, H. (1960): Recherches sur les actions de la loi (Paris, Sirey).

MacCormack, Goeffrey (1972): “Culpa”, SDHI, № 38.

MacCormack, Geoffrey (1974): “Aquilian culpa”, en: Alan Watson (edit.), Daube Noster. Essays in Legal History for David Daube (Edinburgh, Scottisch Academic Press).

Magdelain, André (1987): "La 'loi Poetelia Papiria' et la loi 'Iulia de pecuniis mutuis", en: AA.VV. Estudios en honor de A. d'Ors, (Pamplona, Ediciones Universidad de Navarra).

Marr, A.W. (1962): “Sin. Greek”, en: James Hastings (edit.), Enciclopaedia of Religion and Ethics, tomo XI (Edinburgh, T\&T Clarke).

Martini, Remo (2009): Diritti Greci (Torino, Zanichelli, quinta reimpresión primera edición)

Natali, Nuncio (1970): La lege Aquilia ossia Il damnum iniuria datum (Roma, L'erma di Bretschneider).

Noailles, Pierre (1940-1941): "Nexum", Revue Historique de Droit Français et Étranger, $\mathrm{N}^{\circ} 20-21$.

Orestano, Riccardo (1959): "Azione in generale (storia del problema"), en: Enciclopedia del Diritto, vol. IV (Milano, Giuffré).

Ourliac, Paul y De Malafosse, J. (1960): Derecho romano y francés histórico, tomo I: Derecho de obligaciones (trad. de Manuel Fairén, Barcelona, Bosch). 
Pelloso, Carlo (2011): "Il concetto di 'actio' alla luce della sttrutura primitiva del vincolo obbligatorio", en: Luigi Garofalo (a cura di), Actio in rem e actio in personam (in ricordo di Mario Talamanca), tomo I (Padova, Cedam).

Peñailillo Arévalo, Daniel (2003): Obligaciones. Teoría General y clasificaciones. La resolución por incumplimiento (Santiago, Editorial Jurídica de Chile).

Peppe, Leo (2009): "Riflesioni intorno all'esecuzione personale in diritto romano", AUPA $\mathrm{N}^{\circ} 53$.

Pérez Álvarez, María del Pilar (2011): "La posición del deudor en la historia. De la responsabilidad personal a la patrimonial”, Revista General de Derecho Romano, № 16.

Petit, Eugène (1989): Tratado elemental de Derecho Romano (trad. de la novena edición francesa por Manuel Rodríguez Carrasco, México D.F., Arenas Editor).

Pieri, Geoges (1990): “Obligation”, Archives de Philosophie du Droit. Vocabulaire fundamental du droit, tomo 35.

Pizarro Wilson, Carlos (2008): "Hacia un sistema de remedios por incumplimiento contractual”, en: Alejandro Guzmán Brito (editor), Estudios de Derecho Civil III (Santiago, Legal Publishing).

Prado Rodríguez, Juan Carlos (2010): “Aspectos procesales de la condemnatio in id quod debitor facere potest en favor del insolvente", RIDA $\mathrm{N}^{\circ} 57$.

Prado Rodríguez, Juan Carlos (2012): "La «ratio iuris» del llamado «beneficium competentiae» en el ámbito dotal”, Revista de Estudios Histórico-Jurídicos №34.

Pugliatti, Salvatore (1965): "Delitto (Dei delitti in generale. Premesa)", en: Enciclopedia del Diritto, tomo XII (Milano, Guiffrè).

Purpura (2007): "La publica rappresentazione dell'insolvenza. Procedura esecutive personali e patrimoniali al tempo di Ciceron", en: Iuris Fides Humanistas Ius. Studi Labruna, tomo VII (Napoli).

Purpura, Gianfranco (2009): "La <sorte> del debiore oltre la norte: Nihil inter mortem distat et sortem (Ambrogio, de Tobia X, 36-37)", Iuris Antiqui Historia, 1.

Reinoso, Fernando (1988): "La autonomía de la jurisprudencia romana frente al pensamiento filosófico griego", en: Jaime Roset Esteve (coord.), Estudios en Homenaje al profesor Juan Iglesias, tomo II (Madrid, Seminario de Derecho Romano Urcisino Álvarez).

Robleda, Olis (1972): "El derecho subjetivo en Gayo", en: AA.VV. Studi in onore di Gaetano Scherillo, tomo I (Milano, Istituto Editoriale Cisalpino-La Giolardica).

Robleda, Olis (1977): "La idea del derecho subjetivo en el ordenamiento romano clásico", $B I D R \mathrm{~N}^{\circ} 80$.

Rodhe, Erwin (1994): Psique. La idea del alma y la inmortalidad entre los griegos (trad. de Wenceslao Roces, Madrid, Fondo de Cultura Económica, segunda reimpresión primera edición).

Rodríguez Ennes, L. (2009): "La obligatio y sus fuentes", Revista Internacional de Derecho romano $\mathrm{N}^{\circ} 3$.

Rodríguez Ennes, Luis (2011): “En torno al Derecho romano de obligaciones”, Revista General de Derecho romano, N 17.

SAmper, Francisco (2000): Instituciones Jurídicas de Gayo (Santiago-México-BarcelonaBuenos Aires). 
SAntoro, Raimondo (2001): "Omnia iudicia absolutoria esse", Collana della Rivista di Diritto romano. Atti del Convegno processo civile e proceso penale nell'esperienza giuridica del mondo antico. In memoria de Arnaldo Biscardi (Pontigianano).

SAntoro, Raimondo (2009): "Per la storia dell'obligatio. Il iudicatum facere oportere nella prospettiva dell'esecuzione personale", Iuris Antiqui Storia, vol. I.

Sargento, Manlio (1981): "Pagamento (Diritto Romano)", en: Enciclopedia del Diritto, tomo XXXI (Milano, Giuffe).

Scherillo, Gaetano (1963): "L'adstipulator", RIDA N 10.

Scherillo, Gaetano (1971): "Le definizioni romane delle obbligazioni”, en: AA.VV. Studi in onore di Giuseppe Grosso, vol. IV (Torino, Giappichelli).

Schiavo, Silvia (2009): "Graziano, la cessio bonorum e l'esecuzione personale dei debitori”, Iuris Antiquísima Historia, vol. I.

Schulz, Fritz (1960): Derecho romano clásico (trad. de José Santa Cruz Teigeiro, Barcelona, Bosch).

Soza Ried, María de los Ángeles (2007): “Algunas consideraciones acerca de la cessio bonorum", en: Patricio Carvajal (edit.), Estudios de Derecho romano en homenaje al Prof. Dr. D. Francisco Samper (Santiago, Librotecnia).

Talamanca, Mario (1979): “Obbligazioni (Storia)", en Enciclopedia del Diritto, tomo XXIX (Giuffrè).

Talamanca, Mario (1987): "Processo civile (Diritto romano)", en: Enciclopedia del Diritto, tomo XXXVI (Milano, Giuffrè).

Talamanca, Mario (1990): Istituzioni di Diritto Romano (Milano, Giuffrè).

Tomulescu, C. (1970): "Les trois chapitres de la lex Aquilia”, Iura No 21.

Valditara, Giuseppe (1992): Superamento dell'aestimatio rei nella valutazione del danno aquiliano ed estensione della tutela ai non domini (Milano, Giuffrè).

Valditara, Guiseppe (1994): "Damnum iniuria datum", en: Francisco Javier Paricio Serrano (coordinador), Derecho romano de obligaciones. Homenaje al profesor José Luis Murga Gener (Madrid, Editorial Centro Estudios Ramón Areces).

Vidal Olivares, Álvaro (2007): "La pretensión de cumplimiento específico y su inserción en el sistema de remedios por incumplimiento en el Código civil”, en: Hernán Corral Talciani y María Sara Rodríguez Pinto (coordinadores), Estudios de Derecho Civil II (Santiago, Legal Publishing, segunda edición).

Villey, Michael (1976): "Los orígenes de la noción de derecho subjetivo", en: El Mismo, Estudios en torno a la noción de derecho subjetivo (trad. de Alejandro Guzmán Brito, Valparaíso, Ediciones Universitarias de Valparaíso).

Villey, Michael (1976): "Las instituciones de Gayo y la idea de derecho subjetivo", en: EL mismo, Estudios en torno a la noción de derecho subjetivo (trad. de Francisco Bartolucci, Valparaíso, Ediciones Universitarias de Valparaíso).

Voci, Pasquale (1966): “Esecuzione forzata (Diritto romano)”, en Enciclopedia del Diritto, tomo XV (Milano, Giuffrè).

Zimmermann, Reinhard (1996): The law of obligations. Roman Foundations of the Civilian Tradition (Oxford, Clarendon Paperbacks). 